\title{
Fine structure of the ventral nerve centre and interspecific identification of individual neurons in the enigmatic Chaetognatha
}

\author{
Steffen Harzsch • Carsten H. G. Müller • Verena Rieger • \\ Yvan Perez $\cdot$ Silvia Sintoni $\cdot$ Christian Sardet $\cdot$ \\ Bill Hansson
}

Received: 5 April 2008 / Accepted: 7 October 2008 / Published online: 21 November 2008

(c) The Author(s) 2008. This article is published with open access at Springerlink.com

\begin{abstract}
The enigmatic arrow worms (Chaetognatha) are marine carnivores and among the most abundant planktonic organisms. Their phylogenetic position has been heavily debated for a long time. Most recent molecular studies still provide a diverging picture and suggest arrow worms to be some kind of basal protostomes. In an effort to understand the organization of the nervous system in this clade for a broad comparison with other Metazoa we analysed the ultrastructure of the ventral nerve centre in Spadella cephaloptera by transmission electron microscopy. We were able
\end{abstract}

S. Harzsch $(\bowtie) \cdot$ C. H. G. Müller $\cdot$ V. Rieger $\cdot$ S. Sintoni ·

B. Hansson

Department of Evolutionary Neuroethology,

Max Planck Institute for Chemical Ecology, Beutenberg Campus,

Hans-Knöll-Street 8, 07745 Jena, Germany

e-mail: sharzsch@ice.mpg.de

C. H. G. Müller

Institut für Biowissenschaften,

Allgemeine und Spezielle Zoologie, Universität Rostock,

Universitätsplatz 2, 18051 Rostock, Germany

Y. Perez

Institut Méditerranéen d'Ecologie et de Paléoécologie,

UMR 6116 CNRS, "Persistence and Evolution

of the Biodiversity", Université de Provence,

3 Place Victor Hugo Case 36,

13331 Marseille Cedex 3, France

\section{S. Sintoni}

Fakultät für Naturwissenschaften, Institut für Neurobiologie und Sektion Biosystematische

Dokumentation, Universität Ulm, 89081 Ulm, Germany

\section{Sardet}

Bio Mar Cell, Laboratoire de Biologie du Développement, UMR7009 CNRS/UPMC, Station Zoologique,

Observatoire Océanologique,

06234 Villefranche-sur-Mer Cedex, France to identify six different types of neurons in the bilateral somata clusters by means of the cytoplasmic composition (regarding the structure of the neurite and soma including the shape and eu-/heterochromatin ratio within the nucleus) as well as the size and position of these neurons. Furthermore, our study provides new insights into the neuropil composition of the ventral nerve centre and several other fine structural features. Our second goal was to examine if individually identifiable neurons are present in the ventral nerve centres of four chaetognath species, Sagitta setosa, Sagitta enflata, Pterosagitta draco, and Spadella cephaloptera. For that purpose, we processed whole mount specimens of these species for immunolocalization of RFamiderelated neuropeptides and analysed them with confocal laser-scanning microscopy. Our experiments provide evidence for the interspecific homology of individual neurons in the ventral nerve centres of these four chaetognath species suggesting that the potential to generate serially arranged neurons with individual identities is part of their ground pattern.

Keywords Ventral nerve centre - Spadella cephaloptera . Pterosagitta draco · Sagitta spp. · Ultrastructure .

Immunolocalization $\cdot$ Seriality $\cdot$ Neurophylogeny $\cdot$ Metazoa

\section{Introduction}

The Chaetognatha (arrow worms) are transparent marine carnivores that range in length from 1 to $120 \mathrm{~mm}$ and are among the most abundant planktonic organisms. The taxon comprises more than 120 species from all geographical and vertical ranges of the ocean (Shinn 1997; Nielsen 2001; Kapp 2007). Palaeontological evidence recently showed chaetognaths to be present in the Early Cambrian (approx. 
540-520 Myr ago) Chengjang biota (Vannier et al. 2007). These authors suggest placing them among the earliest active predators and conclude that the ancestral chaetognaths were planktonic with possible ecological preferences for hyperbenthic niches close to the sea bottom. The phylogenetic position of the chaetognaths within the Bilateria is heavily debated (review Harzsch and Müller 2007) and the most recent molecular studies provide a diverging picture. By using Bayesian inference and maximum likelihood method to analyse two broad phylogenomic datasets, Dunn et al. (2008) suggest a sister-group relationship of Chaetognatha to the Lophotrochozoa whereas Marlétaz et al. (2008) propose a most likely position of the Chaetognatha as a sister-group to all Protostomia.

The ventral nerve centre of Chaetognatha is an elongate structure lying between the epidermis and its basement membrane (reviewed in Harzsch and Müller 2007). This neuronal centre controls swimming by initiating contractions of the body wall musculature (Duvert et al. 1980; Duvert and Barets 1983; Duvert and Savineau 1986) and integrates mechanosensory input from the numerous ciliary fence receptors in the epidermis (Bone and Pulsford 1984; Bone and Goto 1991; Shinn 1997; Malakhov et al. 2005). It consists of a central fibrillar neuropil core, flanked by lateral clusters of cell bodies and it is anteriorly connected to the brain by two main connectives (Bone and Pulsford 1984; Goto and Yoshida 1987; Shinn 1997). The ventral nerve centre gives rise to a densely ramifying nervous plexus that provides motor innervation to the body musculature and innervates the ciliary fence receptors (Bone and Pulsford 1984). Some aspects of the fine structure of the ventral nerve centre have been analysed in several species belonging to the genus Sagitta (Ahnelt 1980; Bone and Pulsford 1984; Goto and Yoshida 1987; Bone and Goto 1991). One goal of the present report is to provide further insights into the ultrastructural characteristics of the ventral nerve centre and to compare these between representatives of Spadella and Sagitta. Furthermore, this fine structural analysis will serve as a background for a meaningful analysis of the immunolocalization studies described below.

Studies on the immunolocalization of RFamide-related neuropeptides emphasized serially arranged neurons in the ventral nerve centres of two arrow worm species, Sagitta setosa (Müller, 1947) and Paraspadella gotoi (Casanova, 1990) and suggested the presence of individually identifiable neurons (Bone et al. 1987; Harzsch and Müller 2007; Goto et al. 1992). The concept of individually identifiable neurons is valid for the nervous systems of many protostome taxa. This means that neurons within the central nervous system can be treated as individuals that can be recognized from animal to animal of one species or even in individuals belonging to different species that are more or less closely related (see Burrows 1996 for a review of this concept in Arthropoda). Kutsch and Breidbach (1994) presented a catalogue of features for examining cellular characteristics of individually identifiable neurons in order to explore whether they may be homologous between different arthropod taxa. Their catalogue includes features such as the common ontogenetic origin of neurons, physiological criteria such as the characterization of a neuron as inhibitory or excitatory, biochemical criteria such as the expression of specific neurotransmitters or neuron-specific markers, and morphological criteria such as the position of the neuronal somata in relation to the ganglion framework as well as the course of the neurites and the targets that they innervate. Within the Protostomia, individually identifiable neurons have been shown to be present in the nervous systems of, e.g. Arthropoda (Burrows 1996; Harzsch et al. 2005; Harzsch 2006), Annelida (Stuart et al. 1987; Huang et al. 1998, Gilchrist et al. 1995; Brodfuehrer and Thorogood 2001; Orrhage and Müller 2005; Müller 2006), Nemathelminthes/Cycloneuralia (White et al. 1986; Walthall 1995), basal Mollusca (Friedrich et al. 2002; Voronezhskaya et al. 2002), Plathelminthes (Halton and Gustafsson 1996; Reuter et al. 1998; Reuter and Halton 2001), and Gnathifera (Müller and Sterrer 2004). The presence of at least some individually identifiable neurons in basal deuterostomes such as tunicates (Meinertzhagen 2004; Stach 2005; Meinertzhagen et al. 2004; Imai and Meinertzhagen 2007; Soviknes et al. 2007), and the lancelet (Wicht and Lacalli 2005) indicates that the potential to establish individual identities may not only be present in the ground pattern of Protostomia; but may even date back to the ground pattern of Bilateria. Our previous study on representatives of Sagitta had indicated the possibility that individually identifiable neurons may also be present in Chaetognatha (Harzsch and Müller 2007). The present contribution sets out to explore this question in more detail.

The tetrapeptide FMRFamide (Phe-Met-Arg-Phe-NH2) and FMRFamide-related peptides (FaRPs) form a large neuropeptide family with more than 50 members, all of which share the RFamide motif (reviews: Price and Greenberg 1989; Greenberg and Price 1992; Walker 1992; Dockray 2004; Kriegsfeld 2006; Zajac and Mollereau 2006). This neuropeptide family is widely distributed among invertebrates and vertebrates and an increasing amount of literature on the structural diversity and neurohormonal action of invertebrate FaRPs and other peptides, e.g. in Coelenterata (review Grimmelikhuijzen et al. 1992), Plathelminthes (review Fairweather and Halton 1991; Choi et al. 1996), Mollusca (review Muneoka and Kobayashi 1992), and Arthropoda (Keller 1992; Gaus et al. 1993; Groome 1993; Nässel 1993; Homberg 1994; Nässel and Homberg 2006) highlights a growing appreciation of the importance of these substances. So far, the evidence for the presence of FaRPs in Chaetognatha stems from 
immunocytochemical experiments only (Bone et al. 1987; Goto et al. 1992; Harzsch and Müller 2007) but the sequences of the FaRPs present in this clade are still unknown. The cell bodies of the RFamide-like immunoreactive neurons in arrow worms are located in the lateral cell soma clusters that flank the central neuropil. The previous studies have shown that the RFamide-like immunoreactive neurons are individually identifiable and can be homologized between different specimens within single arrow worm species (intraspecific homology; Kutsch and Breidbach 1994). However, so far it was not known if certain individually identified neurons can also be identified across different species of the Chaetognatha (interspecific homology; Kutsch and Breidbach 1994). Therefore, the second goal of this study was to answer the question if RFamidelike immunoreactive neurons can be individually identified and homologized between four arrow worm species, $S$. setosa, Sagitta enflata (Grassi 1881), Pterosagitta draco Krohn 1853, and Spadella cephaloptera (Busch 1851) based on biochemical and morphological features as laid out by Kutsch and Breidbach (1994).

\section{Materials and methods}

\section{Experimental animals}

For histological, immunohistochemical, and electron microscopical studies, adult specimens of Sagitta setosa (Müller, 1947) (Aphragmophora, Sagittidae) were obtained off Helgoland (North Sea) in August 2006 by horizontal (surface water samples) as well as by vertical (down to $20 \mathrm{~m}$ depth) plankton hauls on Helgoland Roads with the research vessel "MS Aade". Adult specimens of Sagitta enflata (Grassi, 1881) (Aphragmophora, Sagittidae) were obtained in November 2006 by horizontal plankton hauls (surface water samples) ca. 1 nautical mile off the coast of Villefranche-sur-mer (France). Adult specimens of Spadella cephaloptera (Busch, 1851) (Phragmophora, Spallediae) were collected in Sormiou (Marseille, France) in June 2006 and August 2007. A plankton net was grazed over the sea grass beds by snorkelling. Animals were kept in aquaria containing natural seawater $\left(21 \pm 1^{\circ} \mathrm{C}\right)$ at the Université de Provence, Marseille. Specimens of Sagitta bipunctata (Quoy and Gaimard, 1827) (Aphragmophora, Sagittidae) were collected near Cassidaigne (Marseille, France) in October 1997 during a planktonic survey carried out on mesopelagic communities at depth levels of approximately $500 \mathrm{~m}$. Specimens of Sagitta hispida (Conant, 1895) (Aphragmophora, Sagittidae) were collected from the Indian River Lagoon $\left(27^{\circ} 14^{\prime} \mathrm{N}, 80^{\circ} 90^{\prime} \mathrm{W}\right)$ in surface water near Fort Pierce (FL, USA) with a plankton net suitable for capturing macrofauna organisms $(300 \mu \mathrm{m}$ mesh size $)$.
Pterosagitta draco Krohn, 1853 (Aphragmophora, Pterosagittidae) was provided by Gisèle Champalbert and Marc Pagano from the Institut pour la Recherche et le Développement (IRD UR 167 SyRoCo) who collected samples during a mission in the Indian Ocean (Tulear). The immunohistochemical observations reported in this paper are based on the analysis of at least ten specimens for each species except $P$. draco, of which unfortunately only one specimen was available.

Preparation for bright field microscopy and transmission electron microscopy

Adult specimens of $S$. cephaloptera, 3-4 mm in length, were starved for 2 days in order to fix them in an unfed condition. Adult individuals of the species $S$. bipunctata and $S$. hispida (Aphragmophora, Sagittidae) were immediately fixed from fresh plankton samples. A total of ten individuals of $S$. cephaloptera was fixed either by immersing the entire specimen or by cutting the body into three pieces (head, trunk, and tail). The tissues were immersed for $12 \mathrm{~h}$ in a cold solution of Karnovsky's prefixative (Karnovsky 1965), consisting of $2 \%$ glutaraldehyde, $2 \%$ paraformaldehyde, $1.52 \% \mathrm{NaOH}$, and $1.2 \mathrm{~g} \mathrm{D}$-glucose, dissolved in $2.25 \%$ Na-hydrogenphosphate buffer (pH 7.4). After washing in the same buffer $(12 \mathrm{~h})$, the specimens were postfixed for $4 \mathrm{~h}$ in $1 \% \mathrm{OsO}_{4}$ solution (same buffer) at room temperature and, following dehydration in a graded series of acetone, embedded in epoxide resin (Araldit, FLUKA).

Several adult individuals of $S$. bipunctata were fixed without any dissection according to the method developed by Arnaud et al. (1978), including a prefixation for 4-8 h in a cold solution of $2 \%$ glutaraldehyde, $1 \%$ paraformaldehyde, $30 \%$ filtered seawater in $0.2 \mathrm{M}$ Sodium-cacodylate buffer ( $\mathrm{pH} 7.3$; final osmolarity of the fixative was around 1,240 mosm), followed by a 12-h rinse in the same buffer with glucose added. The specimens were postfixed was in $1 \% \mathrm{OsO}_{4}$ (in cacodylate buffer with $\mathrm{NaCl}$ ) at $4^{\circ} \mathrm{C}$ for $1 \mathrm{~h}$. The specimens were dehydrated in a graded series of ethanol and propylene oxide and finally embedded in Epon resin.

About 20 adult individuals of $S$. hispida were fixed by Dr George Shinn (Northeast Missouri State University) in a modified solution after Karnovsky (1965), consisting of the same concentration of chemicals used for fixing S. cephaloptera. The head and the tail were separated from the trunk with a razor blade (1-2 min after immersion into the primary fixative). However, for postfixation a higher concentrated $\mathrm{OsO}_{4}$ solution ( $2 \%$ in $0.2 \mathrm{M}$ phosphate buffer) was used. The trunk of $S$. hispida was then dehydrated in a graded series of ethanol, transferred through three changes of propylene oxide solutions, and embedded in Epon 812.

Serial semithin sections $(1 \mu \mathrm{m})$ were prepared and stained using $1 \%$ toluidine blue in a solution of $1 \%$ Na-tetraborate 
(borax). Serial ultrathin sections were stained with uranyl acetate and lead citrate for $5 \mathrm{~min}$ each and then examined under a Zeiss 902A Transmission Electron Microscope, operated at $80 \mathrm{kV}$. Some of the TEM-images shown in this paper (e.g. Figs. 3a, e, 4h) are photomontages compiled with the ITEM software, from up to 30 single digital micrographs.

\section{Immunohistochemistry}

Specimens were fixed overnight at $4^{\circ} \mathrm{C}$ (or for $4 \mathrm{~h}$, room temperature) in $4 \%$ paraformaldehyde (PFA) in phosphate buffer (PB; 0.1 M, pH 7.4). Immunohistochemistry was carried out on free-floating whole mounts of adult specimens with fluorochrome-conjugated secondary antibodies using standard protocols (Harzsch and Müller 2007). After fixation the tissues were washed in several changes of phosphate buffered saline (PBS) for at least $4 \mathrm{~h}$, preincubated in PBSTX (1\% normal goat serum, $0.3 \%$ Triton $\mathrm{X}-100,0.05 \%$ Naacide) for $1 \mathrm{~h}$ and then incubated overnight in the primary anti-FMRFamide antibody (from rabbit; Diasorin) diluted 1:1,000 in PBS-TX at room temperature. Specimens were then washed for at least $2 \mathrm{~h}$ in several changes of PBS and subsequently incubated in secondary antibodies against rabbit proteins conjugated to the fluorochrome Alexa Fluor 488 (Molecular Probes, obtained by MoBiTec, Göttingen, Germany) for $4 \mathrm{~h}$. Some specimens of $S$. cephaloptera were processed with a histochemical counter stain, a high-affinity probe for actin, by adding Phallotoxins conjugated to Alexa Fluor 546 (Molecular Probes; concentration 200 units $/ \mathrm{ml}$ ) to the secondary antibody in a dilution 1:50. Other samples were counterstained with the nuclear dye bisbenzimide (0.1\%, Hoechst H 33258) for $15 \mathrm{~min}$ at room temperature. Finally, the tissues were washed for at least $2 \mathrm{~h}$ in several changes of PBS and mounted in GelMount (Sigma).

The antiserum we used was generated in rabbit against synthetic FMRFamide (Phe-Met-Arg-Phe- $\mathrm{NH}_{2}$ ) conjugated to bovine thyroglobulin (DiaSorin, Cat. No. 20091, Lot No. 923602). According to the manufacturer, staining with this antiserum is completely eliminated by pre-treatment of the diluted antibody with $100 \mu \mathrm{g} / \mathrm{ml}$ of FMRFamide. We repeated this experiment and preincubated the antiserum with $10^{-4} \mathrm{M}$ FMRFamide $\left(16 \mathrm{~h}, 4^{\circ} \mathrm{C}\right)$. In this control, neuronal structures were not labelled. In an additional control experiment for possible non-specific binding of the secondary antiserum, we omitted the primary antiserum, replaced it with blocking solution, and followed the labelling protocol as above. In this control, staining was absent.

We compared the labelling pattern obtained in our specimens with that in a previous study, in which a polyclonal antiserum to the sequence Arg-Phe-amide was used in $S$. setosa (Bone et al. 1987). This latter antiserum was obtained by immunizing rabbits with synthetic FMRFamide which was coupled via glutaraldehyde to bovine thyroglobulin (Grimmelikhuijzen and Spencer 1984). Incubation of this antiserum with sepharose-bound FMRFamide, FLRFamide, or RFamide abolished all staining and this antiserum has been shown to be most sensitive to the C-terminal sequence-RFamide (-Arg-Phe-NH2; Grimmelikhuijzen 1985). It has been used to label RFamide-like immunoreactive structures, e.g. in a medusa (Grimmelikhuijzen and Spencer 1984) and in several Hydra species (Grimmelikhuijzen 1985). Bone et al. (1987), using the antiserum generated by Grimmelikhuijzen and Spencer (1984) in $S$. setosa, concluded that the chaetognath peptide might be related to any peptide terminating with the sequence $\mathrm{RFa}$ mide. Because the labelling pattern obtained by Bone et al. (1987) closely corresponds to that of S. setosa as found in the present report we conclude that the DiaSorin antiserum that we used most likely also labels any peptide terminating with the sequence RFamide. Therefore, we will refer to the labelled structures in our specimens as "RFamide-like immunoreactive (RFir) neurons" throughout the paper.

Light-microscopic analysis and 3D reconstruction

Digital images of $S$. setosa (Fig. 5a) were obtained with a Zeiss Axioskop fitted with a CCD-1300B digital camera (Vosskühler $\mathrm{GmbH}$ ) and processed with the Lucia Measurement 5.0 software package (Laboratory Imaging Ltd). The specimens of $S$. enflata, $P$. draco, and $S$. cephaloptera were scanned with a Zeiss LSM 510 Meta Confocal LaserScanning Microscope. Those images are based on stacks of between 5 and 10 optical sections (single images are averages of four laser sweeps) of a $z$-series taken at intervals of $1 \mu \mathrm{m}$. Images were black-white inverted and processed in Adobe Photoshop by using the global contrast and brightness adjustment features. The colour coded 3D images in Fig. 4 were generated using the Zeiss LSM viewer software (use red-green glasses to view). Image stacks obtained from $z$-series by the Zeiss LSM 510 Meta were directly loaded into the 3D reconstruction software Amira (Mercury Systems) operated on a Fujitsu Siemens Celsius 560 workstation. The reconstructions in Fig. 7 were generated by using Amira's "create isosurface" module.

\section{Results}

Comparative histology

In adult specimens of Spadella cephaloptera, the ventral nerve centre is located in the anterior third of the animal and extends across ca. two-thirds of the trunk width as visualized by whole-mount histochemical and immunohistochemical labelling of nuclei (Fig. 1). These preparations 


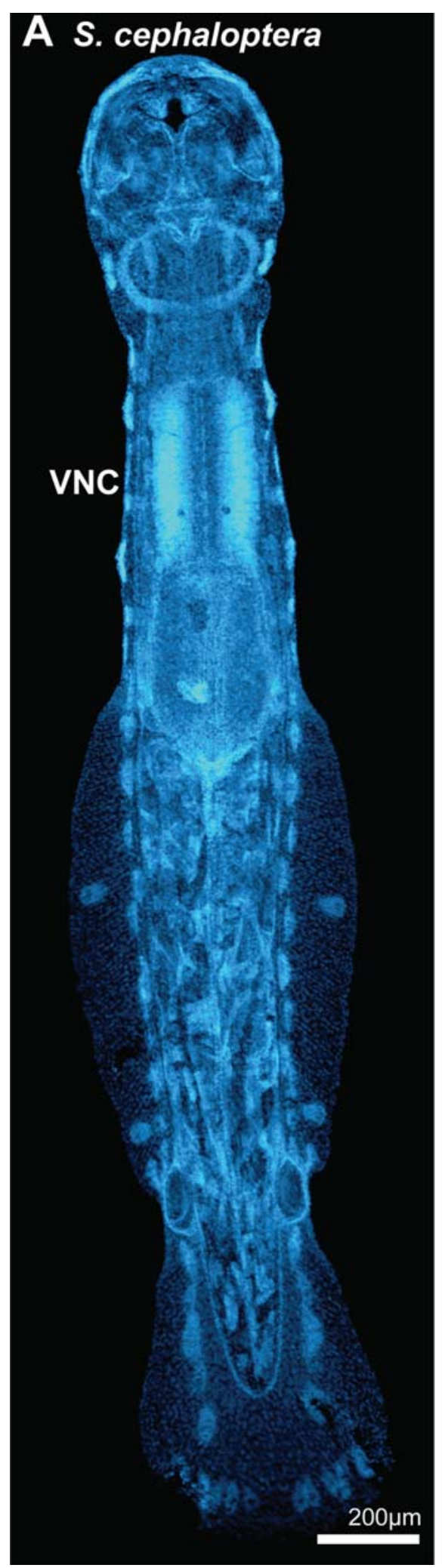

\section{$\mathbf{B}$}
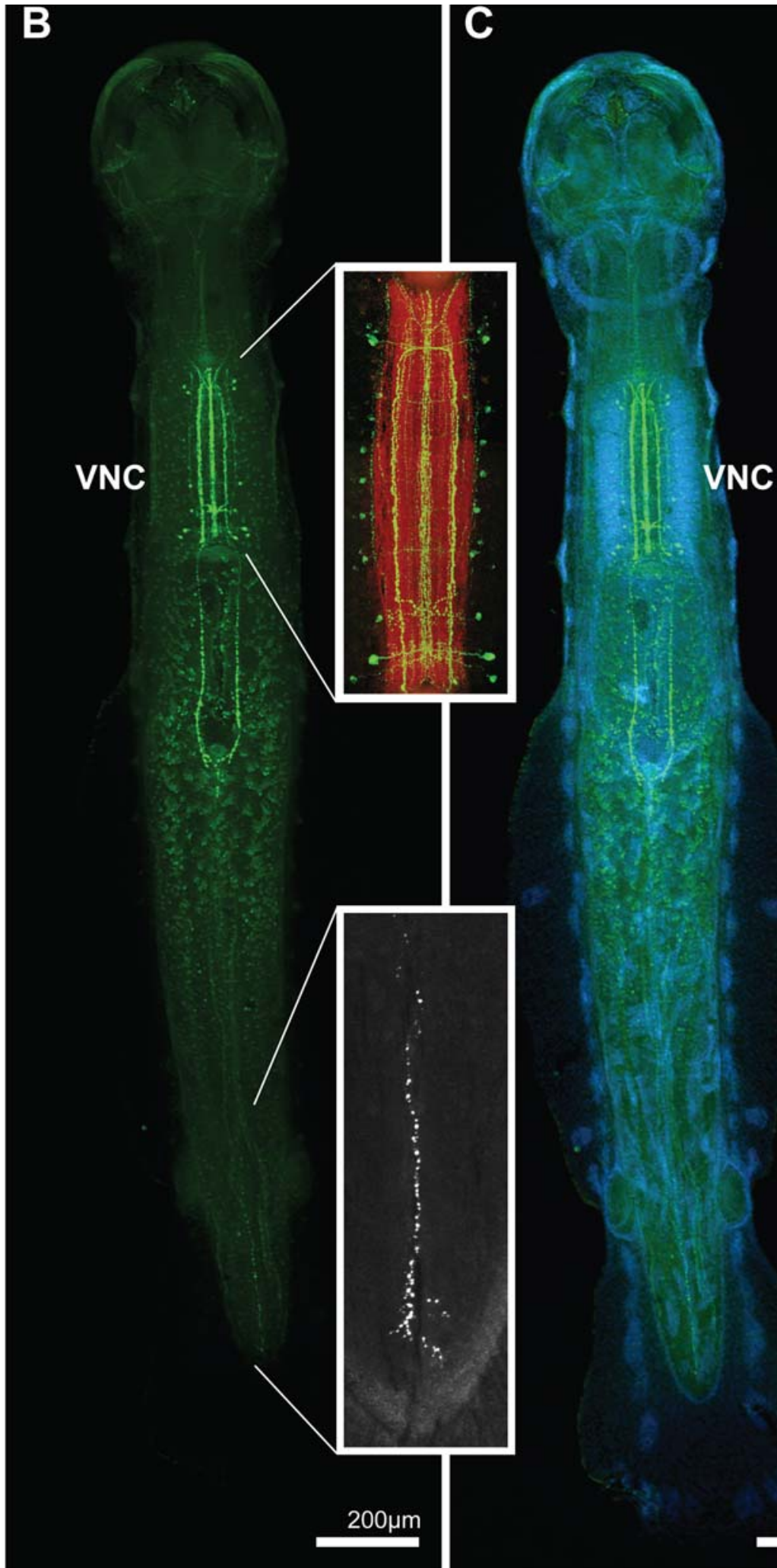

$200 \mu \mathrm{m}$
Fig. 1 Spadella cephaloptera. Whole mounts of adult specimens double labelled for RFamide-like immunoreactivity ( reen), actin histochemistry $(r e d)$, and nuclear staining (blue) to show the localization of the ventral nerve centre (confocal laser-scan microscopy). a-c show the same specimen with the green channel in (a) (RFamide-like immunoreactivity), the blue channel in (b) (nuclear staining with HOECHST), and the overlay of the two channels in (c). The upper inset shows a higher magnification of the ventral nerve centre in another specimen. The central (median) neuropil core is labelled in red (actin histochemistry) and RFamide-like immunoreactivity is labelled green. The lower inset shows a higher magnification of the posteriorly directed fibre that extends from the posterior loop to terminate within the tail. $V N C$ ventral nerve centre 


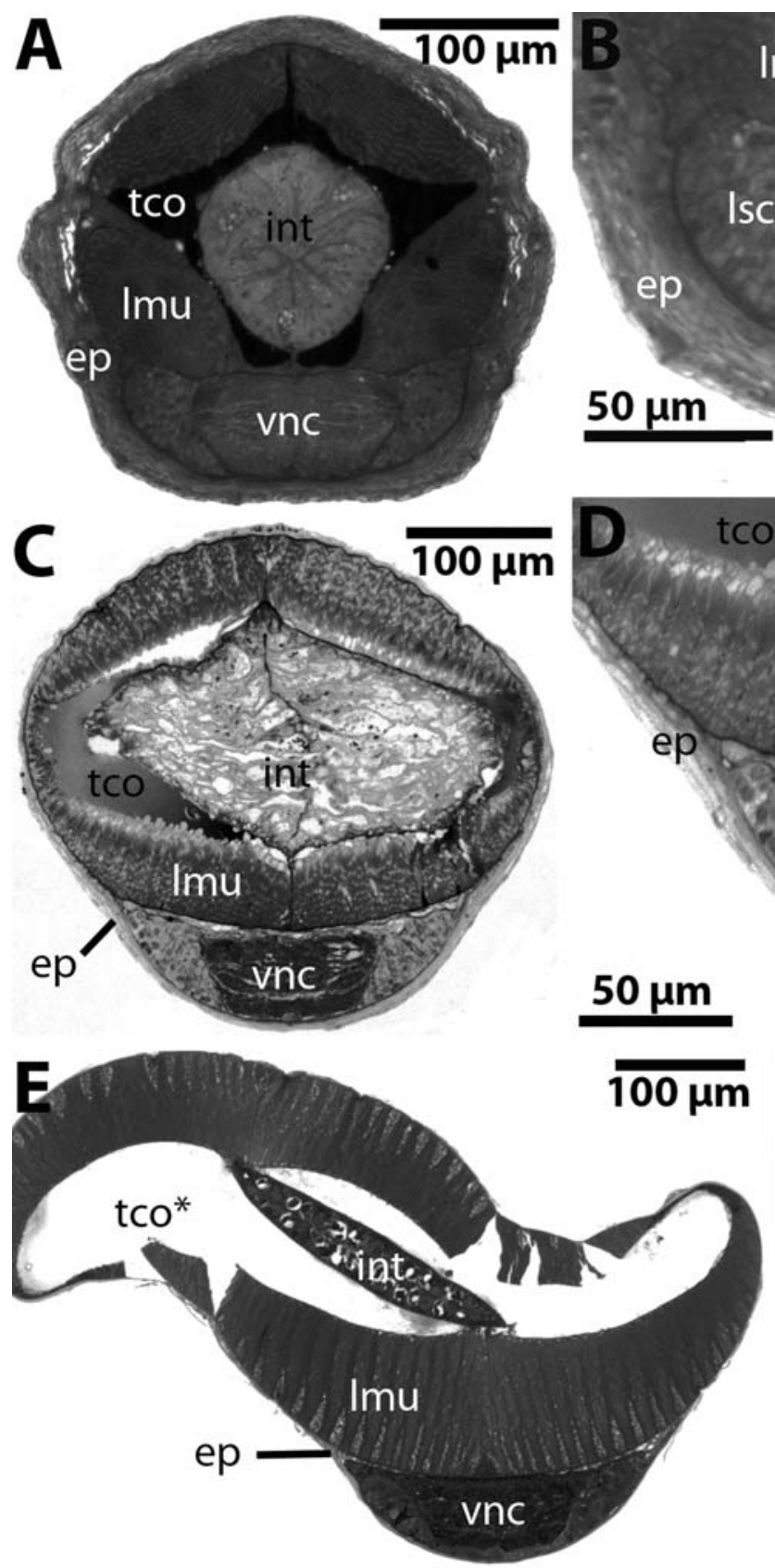

Fig. 2 Spadella cephaloptera $(\mathbf{a}, \mathbf{b})$, Sagitta hispida $(\mathbf{c}, \mathbf{d})$, Sagitta bipunctata $(\mathbf{e}, \mathbf{f})$. Light microscopy to show the comparative anatomy of the ventral nerve centres. a, c, e Cross-sections at the anterior or midlevel of the trunk. b, d, f Higher magnification of the ventral half of the cross-sections. The cross-section in $\mathbf{e}$ is deformed because of the trunk coelomatic space $\left(t c o^{*}\right)$ being collapsed during the fixation process. The double arrowheads in $\mathbf{f}$ indicate one lateral nerve leaving the

and methylene blue-stained cross-sections $(1 \mu \mathrm{m}$, plastic embedded material) show that the ventral nerve centre consists of a central (median) neuropil (mnp; with a multitude of large- and small-diameter profiles of neurites) that is flanked by two lateral clusters of neuronal somata (lsc) and unpaired clusters of neuronal somata (vsc) at the ventral midline of the central (or median) neuropil (Spadella

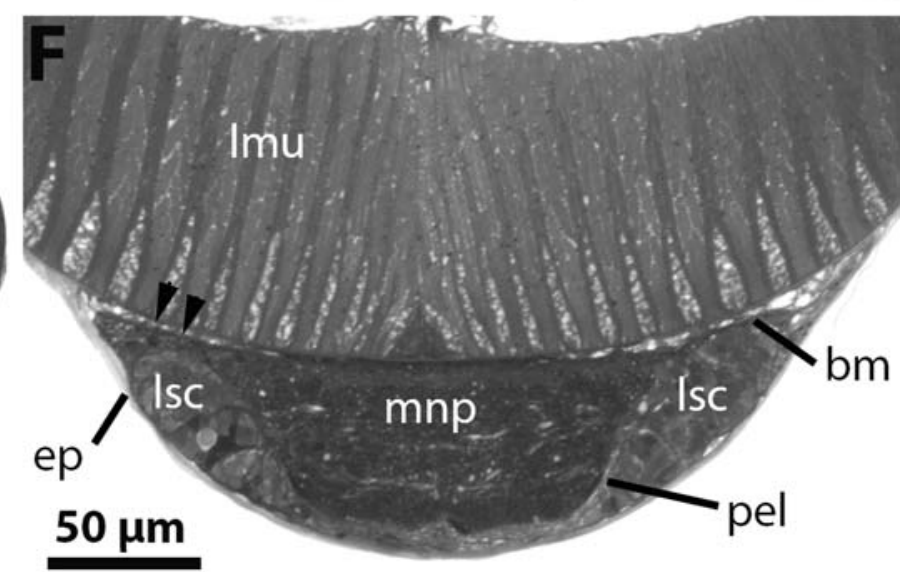

lateral cluster of neuron somata along its dorsal margin. $\mathrm{bm}$ basal matrix (epidermis), ep multilayered epidermis, int intestine, lmu longitudinal trunk musculature, $l s c$ lateral cluster of neuron somata, $m n p$ central (median) neuropil, pel sheath of specialized proximal epidermal cells, tco trunk coelom, vsc ventromedian cluster of neuron somata, $v n c$ ventral nerve centre

cephaloptera: Fig. 2a, b; Sagitta hispida: Fig. 2c, d; Sagitta bipunctata: Fig. 2e, f). The lateral clusters of neuron somata appear shark teeth-like in S. cephaloptera (Fig. 2b), whereas they look triangular or ellipsoidal in $S$. hispida and S. bipunctata (Fig. 2d, f). The ventral nerve centre rests on the basal matrix so that it has a basiepithelial position with respect to the multilayered epidermis (see 
entire Fig. 2). The anterior part of the paired main connectives, which join the cerebral ganglion and the ventral nerve centre, changes from a subepithelial into a basiepithelial position by abrupt disappearance of the basal matrix between the connective neurite bundles and the proximal epidermal layers whereas the paired caudal nerves always remain in a basiepithelial position (data not shown). The neuropil has an elongate-hexagonal form in the benthic $S$. cephaloptera (Fig. 2a, b) and a more trapezoidal or rectangular outline in pelagic sagittid chaetognaths (Fig. 2c, f). Bundles of neurites pass out radially from the dorsolateral edges of the neuropil (arrowheads in Fig. 2f). Over the entire length of the nerve centre, the profiles of large neurites (presumably axons) can be observed that emerge from neurons within the lateral clusters, to enter the neuropil and to transverse the neuropil core where fibres from both sides either seem to make contact or cannot be followed anymore because they take a longitudinal course, respectively (Fig. 2b, d).

The ventral nerve centres of benthic and pelagic species slightly differ in size and proportion to other tissue types in the trunk. In all three species it is slightly over $200 \mu \mathrm{m}$ wide. In $S$. cephaloptera, it is about $75 \mu \mathrm{m}$ high, and in both $S$. hispida and S. bipunctata, it is about $60 \mu \mathrm{m}$ high. In $S$. cephaloptera, it occupies approximately onefourth of a semithin cross-section (dorsoventral extension of the ventral nerve centre in relation to the maximum trunk diameter) whereas in S. hispida and S. bipunctata, the ventral nerve centre has a dorsoventral extension not higher than one-fifth of the maximal dorsoventral diameter of the trunk. One striking difference is the higher width and complexity of the ventral epidermis of S. cephaloptera compared to the other two species. While the distal (also called "outer" or "vacuolated") epidermal cells are constantly arranged in a single-layer pattern, the number of layers made up by the proximal ("inner"), tonofilament-rich epidermal cells is especially high, ranging up to 30 layers (Fig. 3a, e), thus exceeding the number of layers counted in the pelagic taxa $S$. hispida and S. bipunctata (compare Fig. 2b with Fig. 2d, f). In S. cephaloptera, the ventral nerve centre appears to be integrated into the pentagonal cross-profile of the trunk, perhaps as an adaptation to the attachment to sea grass leaves with the ventral surface of the trunk that is equipped with adhesive cells (Fig. 2a).

Ventral nerve centre ultrastructure in Spadella cephaloptera

\section{General}

The basiepithelial or, more precisely, the basiepidermal location of the ventral nerve centre of S. cephaloptera is reliably revealed by transmission electron microscopy. The dorsal margin of the central neuropil as well as of the lateral soma clusters is bordered by extracellular matrix lined by two basal laminae (Fig. 4a, h). Ultrastructural characteristics of the extracellular matrix have been described in great detail by Duvert and Salat (1990). The ventral and lateral margins of the lateral somata clusters and the neuropil are limited by specialized epidermal cells of the proximal type (Figs. 3a, e, $4 \mathrm{~g}-\mathrm{i}$ ). The proximal epidermal cells are characterized by a broad, compact, and moderately electron-dense cytoplasmic layer that contains numerous intermediate filaments and surrounds the inconspicuous, granular cytoplasm which is poor in cytoplasmic organelles (Fig. 3a, e). The innermost proximal epidermal cells, however, seem to be transformed into layers that are much more compressed and elongated. Intermediate filaments are only concentrated at the distal margin of these cells. The packing of the intermediate filaments appears much denser, so that the layer electron optically looks darker (Figs. 3a, b, e, 4d, g, h, l). Along the contact zone between the lateral soma clusters and the neuropil the epidermal wrapping layer resembles a meshwork of strongly ramified cytoplasmic processes which also contain microtubules (Fig. 4h-i). Tangential sections through that transition zone show the presence of gaps through which neurite bundles can pass from the lateral somata clusters (Fig. 3a, 4k; see also below).

The neuropil comprises an elaborated system of neuronal processes. Along the mediosagittal plane, a majority of thin longitudinal neurites (most of them assumed to be axonal strands) can be observed. Synapses are observed in most parts of the neuropil, but are particularly abundant along or near the mediosagittal plane as well as parallel to the dorsal margin close to the basal matrix. A considerable variety of synaptic vesicles confirms the assumed diversity of neuron types (data not shown). At irregular intervals, bilateral pairs of neurite bundles emerge radially from the dorsolateral edge of the neuropil (Fig. 51) and then turn into the intraepidermal nerve plexus or make contact to the ciliary fence organs (data not shown).

\section{Individual neuron types}

In addition to the individual identification of certain neuron types with the aid of immunohistochemical markers (see below), we were also able to distinguish some conspicuous neurons on the ultrastructural level by means of their cytoplasmic composition and structure of the nucleus, as well as size and position.

In all regions of the lateral somata clusters, we detected characteristic neurons with a large, spacious soma containing numerous small and rounded mitochondria of the tubular type, a large, polymorphous, often pierced-looking 


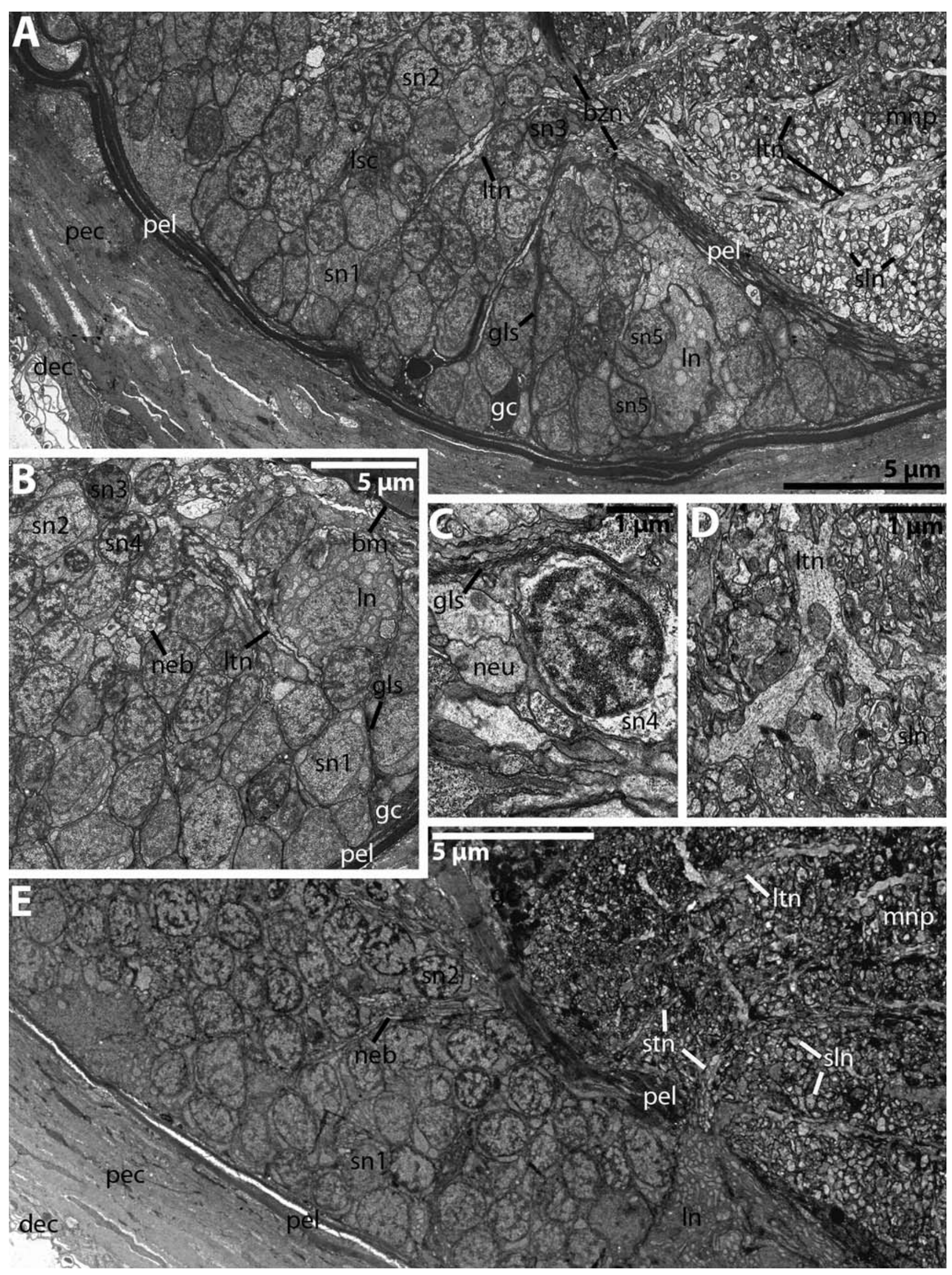


4 Fig. 3 Spadella cephaloptera. Transmission electron microscopy; structure and neuron typology within the ventral nerve centre. a Crosssection of the anterior portion of the ventral nerve centre (left half) showing from left to right the multilayered epidermis, the lateral cluster of neuron somata $(l s c)$ and the central (median) neuropil (mnp). b Higher magnified transverse view of the median region of one lateral cluster of neuron somata comprising various types of neurons. $\mathbf{c}$ Crossprofile of a type four neuron in a lateral neuron cluster (sn4). d Highly magnified transverse view of a mediolateral sector within the median neuropil displaying one large and branched fibre probably emitted from a type four neuron. e Cross-section of the median portion of the ventral nerve centre (left half). $b m$ basal matrix (epidermis), bzn zone of neurite bundles (mostly axons) breaking through the proximalmost epidermal sheath, dec distal epidermal cells, $g l s$ glial sheath, $g c$ glialike cells, $\ln$ large neuron type rich in small mitochondria, ltn large transverse fibre profiles, neb bundle of neurites heading towards the breakthrough zone, neu neurite, pec proximal epidermis cells, pel sheath of specialized proximal epidermal cells, $\sin$ longitudinal fibres with small diameters, sn $1-5$ various neurons of small diameters (types 1-5), stn bundle of small and electron lucent transverse fibres

nucleus, many Golgi stacks, opaque vacuoles, and a strongly developed rough endoplasmic reticulum (neurons labelled "In" in Fig. 3a, b, e; see also Figs. 4b, d). These "large neurons" may stand alone or are grouped together to units of up to three cells and are mostly located close to the ventromedian margin of the somata cluster (Figs. 3a, e). They taper at their inner margin and send out long neurites, $1-3 \mu \mathrm{m}$ in diameter. These neurites possess neurotubules and many mitochondria, their processes pierce the sheath of specialized proximal epidermal cells, and extend into the neuropil which they transverse (Figs. 3e, 4c). The size of these neurons and their unique cytoplasmic composition indicates a high metabolic activity as is the case, e.g. in neurosecretory cells or cells that have to maintain a large dendritic/axonal investment such as motorneurons or command neurons.

In the anterior and median region of the lateral somata clusters, there are other fibres of similarly large diameters, the origin of which we could not trace (ltn in Fig. 3a, b, d). These profiles show a high abundance of neurotubules, have a weakly osmiophilic cytoplasm and include only a few mitochondria. On their way to the neuropil core, these neurites may branch and extend towards dorsal and ventral directions (Fig. 8d). The fibres were not seen to make synaptic contacts with smaller neurites regardless of whether they run longitudinal or transversal through the neuropil.

Apart from the large neurons, several types of smaller neurons can be distinguished mainly based on differences in the structure and shape of the nucleus and of the cytoplasm. For example, the small "type four neurons" have ovoid somata, approximately $3 \mu \mathrm{m}$ in diameter. They seem to be restricted to regions near the main breakthrough zones for neurite bundles (sn4 in Fig. 3b, c). Their nucleus is always circular and displays a voluminous portion of extremely osmiophilic heterochromatin, well contrasting with the weakly osmiophilic euchromatin (Fig. 3c). All other unambiguously identifiable neuron types $(s n 1, s n 2, s n 3, s n 5)$ have the same dimensions as sn4 (Fig. 3a, b, e), but are more frequent and widespread in the lateral somata clusters (e.g. Fig. 3a, b). They possess nuclei with a different eu-/ heterochromatin ratio and produce much thinner neurites that fasciculate and enter the neuropil bundles. "Type one neurons" (snl) are mostly concentrated along the lateral (outer) margins of the lateral somata clusters (Fig. 3a, e). Their cytoplasm is endowed with many medium-sized, elongated mitochondria (tubular type). The nucleus has a sac-like or ovoid shape; the caryoplasm displays only diffuse portions of heterochromatin. The nucleus itself barely contrasts with the surrounding cytoplasm (e.g. Fig. 4h, i, k). In contrast, "type two neurons" $(s n 2)$ are characterized by a moderately electron-dense cytoplasm, poorly supplied with organelles, polymorphous nuclei with only little, but well contrasted heterochromatin (Figs. 3a, b, 4e, h). This cell type is also found to be common in small aggregations of neuron somata oriented medioventrally subjacent to the neuropil and aligned in a stringof-pearls pattern when examined in sagittal sections (Fig. 4g). "Type three neurons" $(s n 3)$ seem to be predominant along the inner half of the lateral somata cluster. On the level of the nucleus, the moderately osmiophilic cytoplasm is quite spacious and equipped with many mediumsized, partly branched mitochondria (tubular type), smooth and rough ER cisternae, free ribosomes, and occasionally also Golgi stacks. The circular nucleus has a considerable portion of heterochromatin whereas the euchromatin portion does not contrast as clear as observed in the other neuron types described (Figs. 3a, b, 4f, h). Neurons herewith labelled as "type five neurons" ( $(n 5)$ very much resemble those of type four (cytoplasmic composition, shape, and ultrastructural appearance of nuclei), but can be clearly differentiated from them by their location, being either in the direct vicinity of the large neurons or penetrating their somata, and being wrapped by layers with glia-like characteristics (Figs. 3a, 4d). The sheath layer of the soma is continued down to the region where the primary neurite originates (Fig. 4j). On approaching the inner border of the lateral somata zone, the small neurites of the neuron types 1-4 fasciculate into distinct bundles (see Fig. $4 \mathrm{~h}, \mathrm{j}$ and further description below). All neurites seem to converge at the inner midlateral region of the lateral soma clusters (Fig. 9h). At the lateral tips of the neuropil the epidermal sheath layer(s) is/are pierced and let through the joint neurite bundles. Above and below this main break-through zone there are smaller perforations of the epidermal sheath layer(s) which are traversed by smaller neurite bundles (Fig. 4k). 

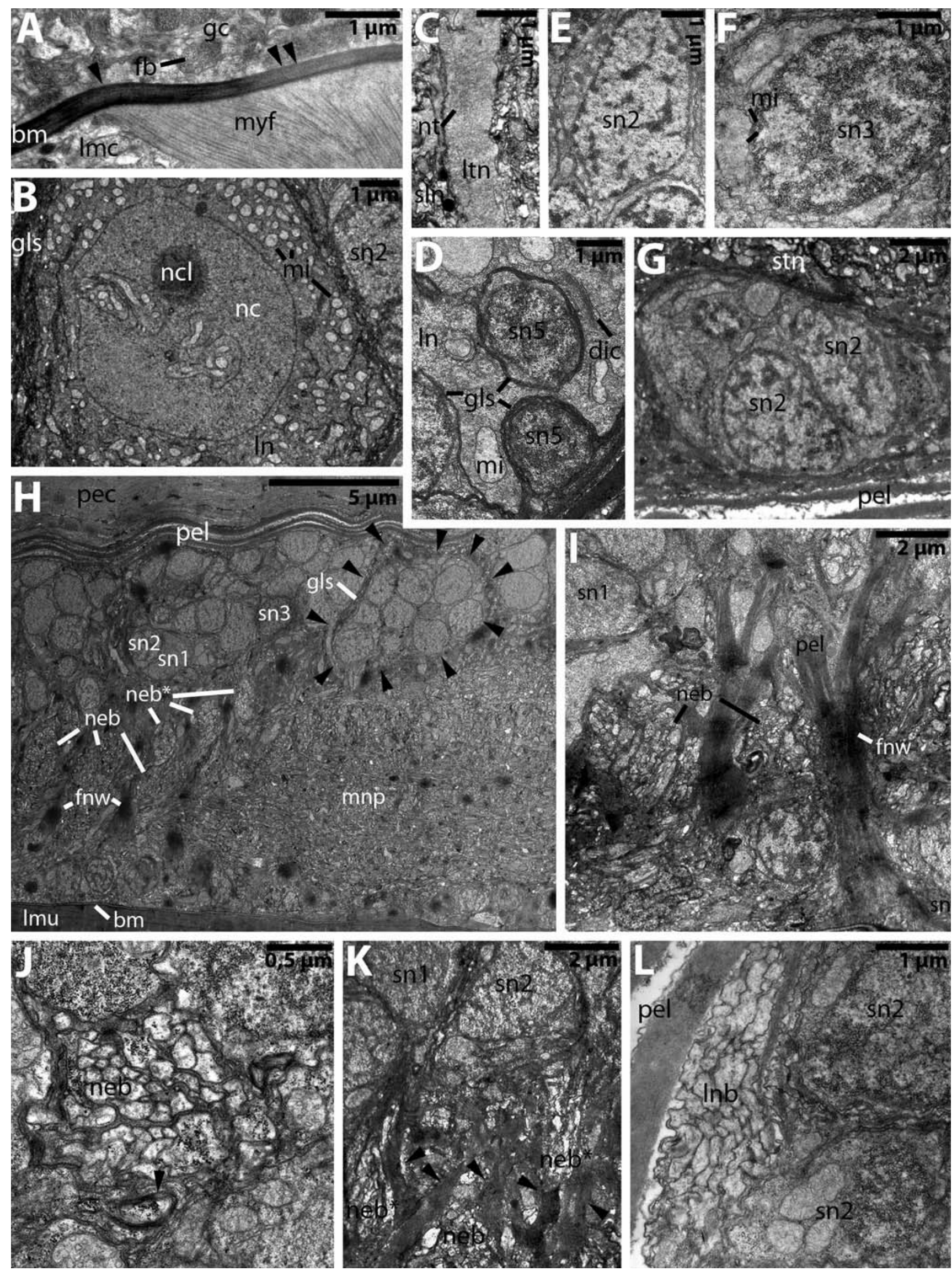
Fig. 4 Spadella cephaloptera. Transmission electron microscopy; structure and neuron typology within the ventral nerve centre. a Longitudinal section through the dorsal margin zone of the ventral nerve centre showing peripheral glia-like cells $(g c)$ enriched with compartments of fibrillous material $(f b)$ and associated with the basal matrix $(\mathrm{bm})$. Note the inhomogeneity of the basal matrix changing from high osmiophilic, fibril-rich (single arrowhead) to moderate osmiophilic, lesser fibrillous (double arrowheads) areas. b Transverse portrait of the nuclear region of a large neuron $(\ln )$ containing a frayed-looking nucleus $(n c)$ and high numbers of small rounded mitochondria ( $m i)$. c Highly magnified cross-section through a large fibre running transversally towards the centre of the central (median) neuropil. d-g Profiles of clearly identifiable neuron types (d-f cross-sections, $\mathbf{g}$ longitudinal section): d Strongly myelinized single type five neuron (sn5) running through one large neuron $(l n)$, e type two neuron $(s n 2)$, f type three neuron ( $s n 3)$, g aggregated type two neurons ( $s n 2)$ placed medioventrally subjacent to the central (median) neuropil. h Slightly oblique longitudinal section through the transition zone between one lateral cluster of neuron somata and the periphery of the central (median) neuropil ( $m n p)$. Note the iterated arrangement of different neurite bundles $\left(n e b, n e b^{*}\right)$ in the breakthrough area heading towards the centre and of the package-like pattern of somata within the lateral cluster (one package marked by arrowheads). i Longitudinal view of the transition zone described for $\mathrm{H}$. Transverse neurite bundles (neb) are separated by ramified, microtubule-rich processes $(f n w)$ of specialized proximal epidermal cells enveloping the entire ventral nerve centre ( $p e l)$. j Section through one transverse neurite bundle running towards the sheath of specialized proximal epidermal cells ( $p e l$ ). Note the single neurite ensheathed by glial processes (arrowhead). k Longitudinal section through the breakthrough region demonstrating two different types of bundles of small neuritis. One is cut transversally and emerged from neurons oriented medially within the lateral cluster (neb), the other comes from neurons located more dorsally and having an electron-lucent cytoplasm $\left(n e b^{*}\right)$. I Bundle of lateral neurites $(\ln b)$ leaving the lateral cluster of neuron somata at its dorsolateral margin and piercing the sheath of specialized proximal epidermal cells ( $p e l$ ). dic Golgi stack, gls glial sheath, lmc longitudinal trunk musculature cell, lmu longitudinal trunk musculature, ltn large transverse fibre profiles, mi mitochondrion, myf myofilament structure, ncl nucleolus, pec proximal epidermis cells, $\sin$ longitudinal fibres with small diameters, sn 1-5 various neurons of small diameters (types 1-5), stn small and electron lucent longitudinal fibres

\section{Glia-like cells and grouping of neurons}

Cells with glial characteristics such as extremely osmiophilic cyto- and caryoplasm are often arranged around the lateral periphery of the lateral somata clusters $(\mathrm{gc}$ in Fig. 3a, b) and the entire neuropil (Fig. 4a). From various regions of the soma, the glia-like cells emanate thin cytoplasmic processes that extend between the interneuronal spaces and give rise to a multilayered sheath around groups of 10-20 neurons as seen in both cross- and longitudinalsections (Fig. 4h). Within such an assembly neuronal somata, glia-like sheaths are much less clear and, if present, are composed of one single layer (Figs. 3a, b, e, 4e, h). The clearly separated packages of somata seem to be aligned in a serially repeated pattern, but this issue needs further analysis. Glia-like wrapping of single somata (Fig. 4d) or neurites (Fig. 4j) is only occasionally seen in the lateral clusters, but is considered typical for "type five neurons" (see above).
RFamide-like immunoreactivity

\section{Previous studies in Sagitta setosa}

RFamide-like immunoreactive (RFir) neurons have previously been reported to be present in $S$. setosa (Bone et al. 1987) and Paraspadella gotoi (Goto et al. 1992), yet these authors did not describe the labelling pattern in greater detail. Harzsch and Müller (2007) also studied S. setosa and provided a detailed analysis of RFir elements in the ventral nerve centre of this species. We will briefly summarize this labelling pattern here to serve as a basis for the comparison with $S$. enflata and S. cephaloptera.

In the ventral nerve centre of $S$. setosa, the cell bodies of the RFir neurons are located within the lateral soma zones, mostly close to the interface between the neuropil core and the soma clusters, whereas longitudinal RFir fibre tracts are restricted to the ganglion core (Fig. 5a; reprinted from Harzsch and Müller 2007; copyright for this figure is held by Harzsch and Müller). Three main longitudinal tracts of RFir fibres can be distinguished: the medial bundle (MB), the bilaterally paired intermediate bundles (IB), and the paired lateral bundles (LB; Fig. 5a) that run along the lateral borders of the neuropil core. The RFir neurons, all of which are unipolar, can be subdivided into two different populations: a first series of neurons with lateral somata ( $L 1-4$; small circles in Fig. 5a) in the anterior third of the nerve centre and a second series of slightly larger dorsal neurons (D1-5; large circles in Fig. 5a; and see Fig. 6a) in the posterior two-thirds of the nerve centre. The somata of these are located slightly more dorsally than those of the lateral neurons. The arrangement of the most anterior lateral neurons displayed some variation between individual specimens of $S$. setosa and in addition to the neurons $L 1$ and $L 2$ that were identified consistently in all analysed specimens; additional neurons were present in some specimens (small circles labelled with a question mark in Fig. 5a; see Harzsch and Müller 2007). Contrary to $L 1$ and $L 2$, the neurons $L 3, L 4$, and $D 1-D 6$ (D6 is $D 7$ in the new nomenclature used in this paper as will be explained below, page [20]) were reliably present in all analysed specimens of $S$. setosa and hence represent typical examples for individually identifiable, bilaterally symmetrical arranged neurons. The neurons D1-D5 have an identical morphology and appear to be serially repeated clones (Fig. 6a). Their neurites exit the soma in a medial direction to enter the neuropil core at a right angle to the anterior-posterior axis. The neurites of cells D1-D5 all cross-over the lateral longitudinal bundle to join the intermediate bundle (Fig. 6a; Harzsch and Müller 2007).

\section{Sagitta enflata}

Concurrent with the much larger size of $S$. enflata compared to $S$. setosa, the ventral nerve centre in the former 


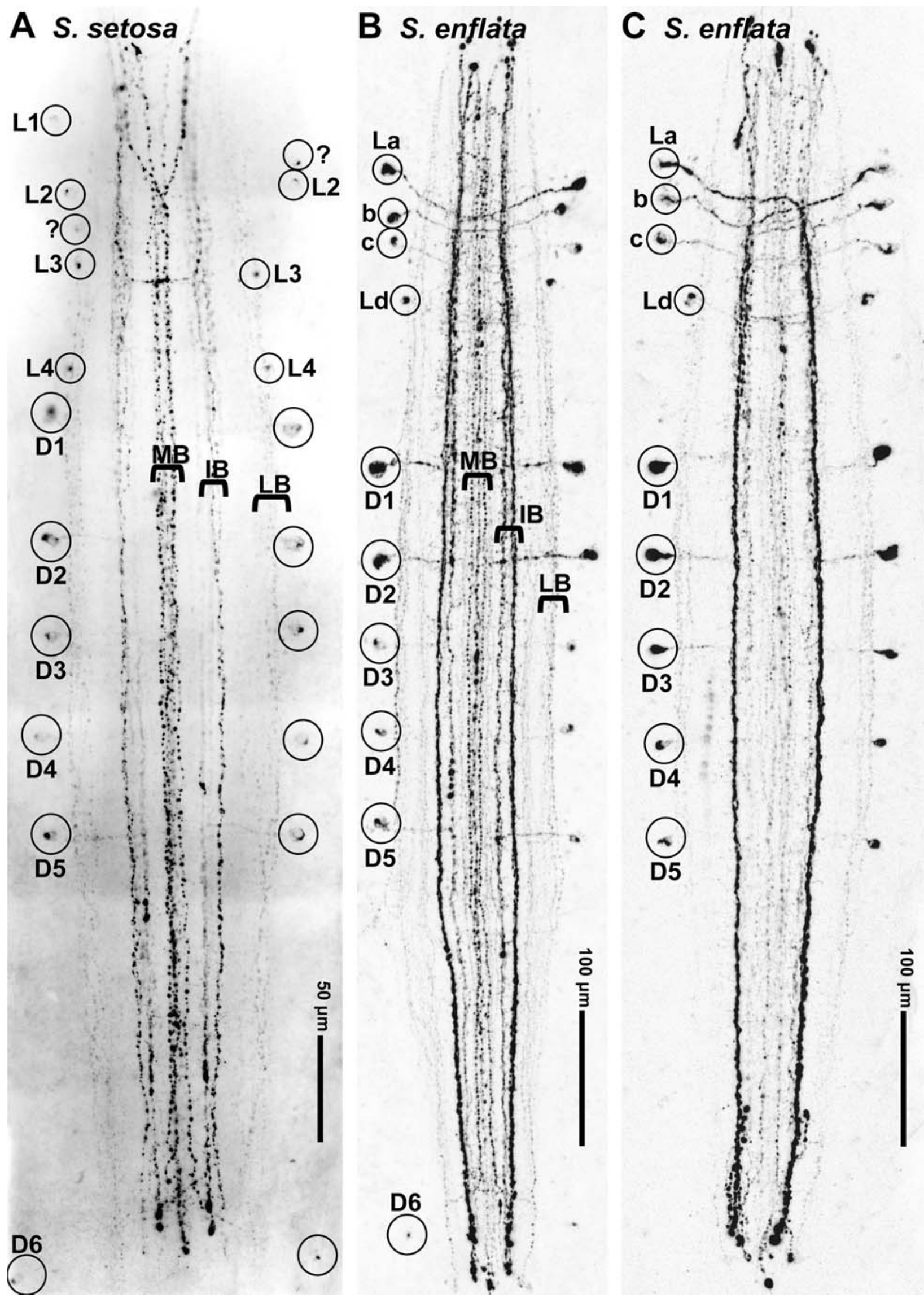


4 Fig. 5 Sagitta setosa (a) and Sagitta enflata $(\mathbf{b}, \mathbf{c})$. Ventral views of whole mount specimens, confocal laser-scan microscopy. Localization of RFamide-like immunoreactivity in the ventral nerve centres of different specimens. Figure $1 \mathbf{a}$ is reprinted from Harzsch and Müller (2007: BMC Frontiers in Zoology, copyright held by S. Harzsch and C.H.G. Müller). a Is a photomontage of black-white inverted fluorescence micrographs, $\mathbf{b}$ and $\mathbf{c}$ are confocal laser-scan images. Individually identifiable neurons are encircled and labelled with letters (for details see text). Abbreviations identify the longitudinal bundles: $I B$ intermediate bundle, $L B$ lateral bundle, $M B$ medial bundle

species is about twice as long and as broad as that of $S$. setosa. The three main longitudinal tracts of RFamide-like immunolabelled (RFir) fibres that are present in S. setosa are also apparent in $S$. enflata: the medial bundle (MB), the bilaterally paired intermediate bundles (IB), and the paired lateral bundles (LB; Figs. 5b, c, 7a, b). The medial bundle is composed of an unpaired median fibre that is to the left and right flanked by paired fibres (Fig. 7b). The intermediate longitudinal bundle is composed of an inner and an outer portion (Fig.7a) similar to the pattern in S. setosa (Harzsch and Müller 2007). The fibres in the more diffuse lateral bundle are weakly labelled compared to the median and intermediate bundles (Fig. 7a). Anteriorly and posteriorly, most fibres within the medial and intermediate bundles terminate in heavily labelled spherical structures and do not appear to proceed further anteriorly or posteriorly
(Figs. 5b, c, 8b). Three-dimensional reconstructions of confocal image stacks using Amira software showed that all fibres within the RFir fibre network are arranged in roughly the same horizontal dorsoventral level. The labelling pattern of RFir somata was identical in all specimens that we analysed as exemplified by the two specimens shown in Figs. 5b, c, 6b, c, 8a, B, suggesting intraspecific homology of the neurons. As in $S$. setosa, two different populations of RFir neurons are present in the ventral nerve centre of $S$. enflata: the series of lateral neurons ( $L a-d$; small circles in Fig. 5b, c; and see Fig. 8a, b) in the anterior part of the nerve centre and the second series of slightly larger dorsal neurons (D1-7; large circles in Figs. 5b, c, 6b, c,7a, 8c). The arrangement of the four anterior lateral neurons was consistent between individual specimens of $S$. enflata. These neurons hence represent typical examples of individually identifiable, bilateral symmetrically arranged neurons (Fig. 8a, b). However, we could not determine unambiguously, which of the La-d neurons in S. enflata may be equivalent to the L1-4 neurons in $S$. setosa, because in the latter species the course of the neurites of these cells could not be followed over any reasonable distance (Harzsch and Müller 2007). In S. enflata, the neurites of all four $L$ neurons seem to cross the nerve centre contralaterally to target the intermediate bundle (Fig. 8a, b). As in S. setosa, the D1-D6 neurons did reliably label in all analysed specimens

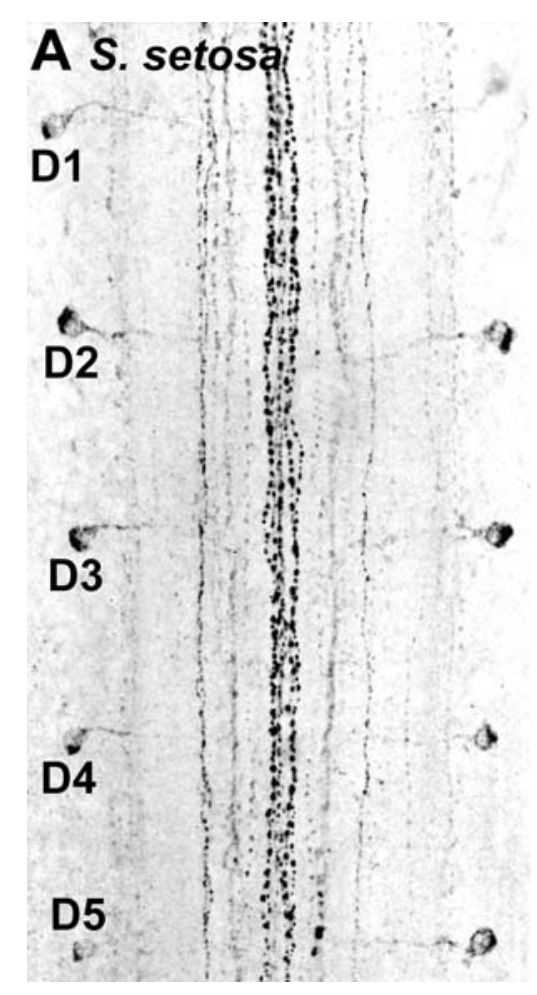

Fig. 6 Sagitta setosa (a) and Sagitta enflata (b, c). Ventral views of whole mount specimens, confocal laser-scan microscopy (black-white inverted images). Localization of RFamide-like immunoreactivity in
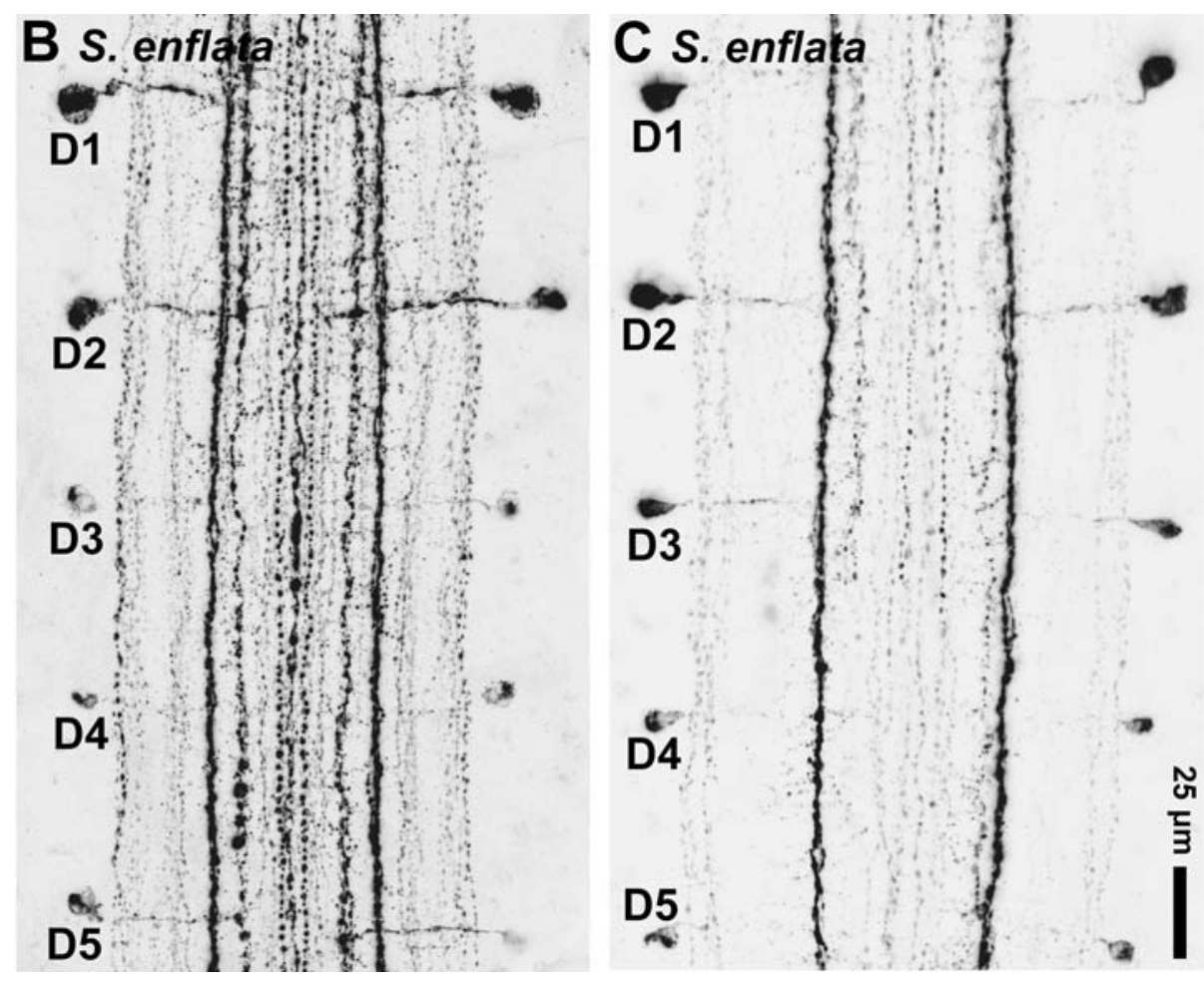

the ventral nerve centres of different specimens. The individually identified $D$ neurons that can be homologized between the two species are labelled with letters D1-D5 (for details see text) 


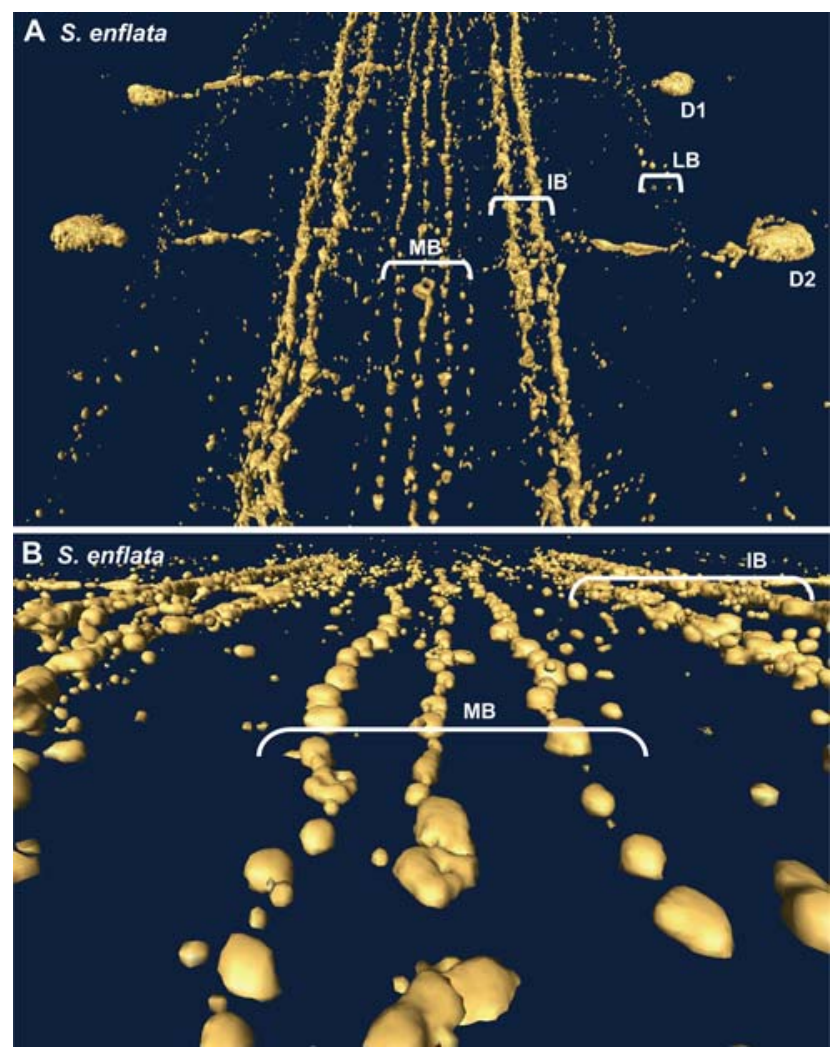

Fig. 7 Sagitta enflata. Computer-based 3D surface reconstruction (Amira) of RFamide-like immunoreactive material in the ventral nerve centre viewed from a posterior/ventral perspective. a Shows the DI and $D 2$ neurons and $\mathbf{b}$ is a higher magnification of the median fibre bundle (for details see text). Abbreviations identify the longitudinal bundles: $I B$ intermediate bundle, $L B$ lateral bundle, $M B$ medial bundle

of $S$. enflata and have a similar morphology in both species. One exception is that in S. enflata, D1 and D2 were slightly larger than the other $D$ neurons (Figs. 6b, c). Nevertheless, D1-D5 can be homologized between the two Sagitta species examined here ("interspecific homology" according to the nomenclature established by Kutsch and Breidbach, 1994) because in all specimens their neurites exit the soma in a medial direction and enter the neuropil core at a right angle to cross-over the lateral longitudinal bundle (LB) and target the inner fibres of the intermediate bundle (IB; Figs. 6b, c, 7a, 8c). However, in some specimens tiny branches of $D 1$ and $D 2$ were present that appeared to proceed further medially from the contact point with the intermediate bundle (Figs. 7a, 8c). A similar observation has already been reported from $S$. setosa (Harzsch and Müller 2007: Figs. 8c, d).

\section{Pterosagitta draco}

Unfortunately, we were able to process only one specimen of $P$. draco. The labelling pattern was virtually identical to that in the two Sagitta species studied. These similarities
Fig. 8 Sagitta enflata. Ventral views of whole mount specimens, confocal laser-scan microscopy. Details of the RFamide-like immunoreactive system in the ventral nerve centre. Images are colour coded 3D; use red-green glasses to view. $\mathbf{a}, \mathbf{b}$ The series of $\mathrm{L}$ neurons in two different individuals. $\mathbf{c}$ Higher magnification of the $D 1$ and $D 2$ neurons. Abbreviations identify the longitudinal bundles: $I B$ intermediate bundle, $L B$ lateral bundle, $M B$ medial bundle

includes the three main longitudinal tracts of RFamide-like immunolabelled (RFir) fibres, the medial bundle (MB), the bilaterally paired intermediate bundles (IB), and the paired lateral bundles (LB; Fig. 9a, b). Furthermore, the series of lateral $(L)$ neurons and the second series of slightly larger dorsal neurons $(D 1-7)$ is also present in $P$. draco (Fig. 9a, c, d). Although the quality of the stain did not match that of both Sagitta species, we were nevertheless able to follow the course of primary neurites of D1-5 (Fig. 9c) and D7 (Fig. 9d). They most closely resemble those in the two Sagitta species.

\section{Spadella cephaloptera}

As in both species of Sagitta and in $P$. draco, three main longitudinal tracts of RFamide-like immunolabelled (RFir) fibres are present in $S$. cephaloptera, the medial bundle (MB), the bilaterally paired intermediate bundles (IB), and the paired lateral bundles (LB; Fig. 10; and upper inset in Fig. 1b). The fibres in the medial and intermediate bundles are more strongly labelled than the lateral bundles. As in Sagitta species, most fibres within all three bundles are confined to the ventral nerve centre and only few labelled fibres proceed further anteriorly into the main connectives $(\mathrm{CO}$; Fig. 10b) or posteriorly into the caudal tracts (CT). Concurrent with the observations by Goto et al. (1992) on Paraspadella gotoi, we recorded that the RFir fibres that leave the ventral nerve centre posteriorly in S. cephaloptera form a caudal loop (CL; Figs. 1b, 10a). In some specimens, fine fibres branched off from the posterior end of the caudal loop (inset in Fig. 1a) to proceed further caudally (lower inset in Fig. 1b). These branches give rise to what appears to be a single labelled fibre that extends medially downwards to the tail of the animal where it terminates in varicose endings (lower inset in Fig. 1b). The labelling pattern of RFir somata was identical in all specimens that we analysed as exemplified by the two specimens shown in Figs. 10b, c suggesting, as in Sagitta species, intraspecific homology of the neurons. Once again, two different populations of RFir neurons seem to be present in the ventral nerve centre of $S$. cephaloptera, the anterior series of $L$ neurons ( $L a-d$; small circles in Fig. 10b, c) and the second series of $D$ neurons (D1-7; large circles in Fig. 10b, c). The distinction between the $L$ and $D$ series could be made because, as in S. enflata, the soma of $L d$ is clearly located more medially than that of 


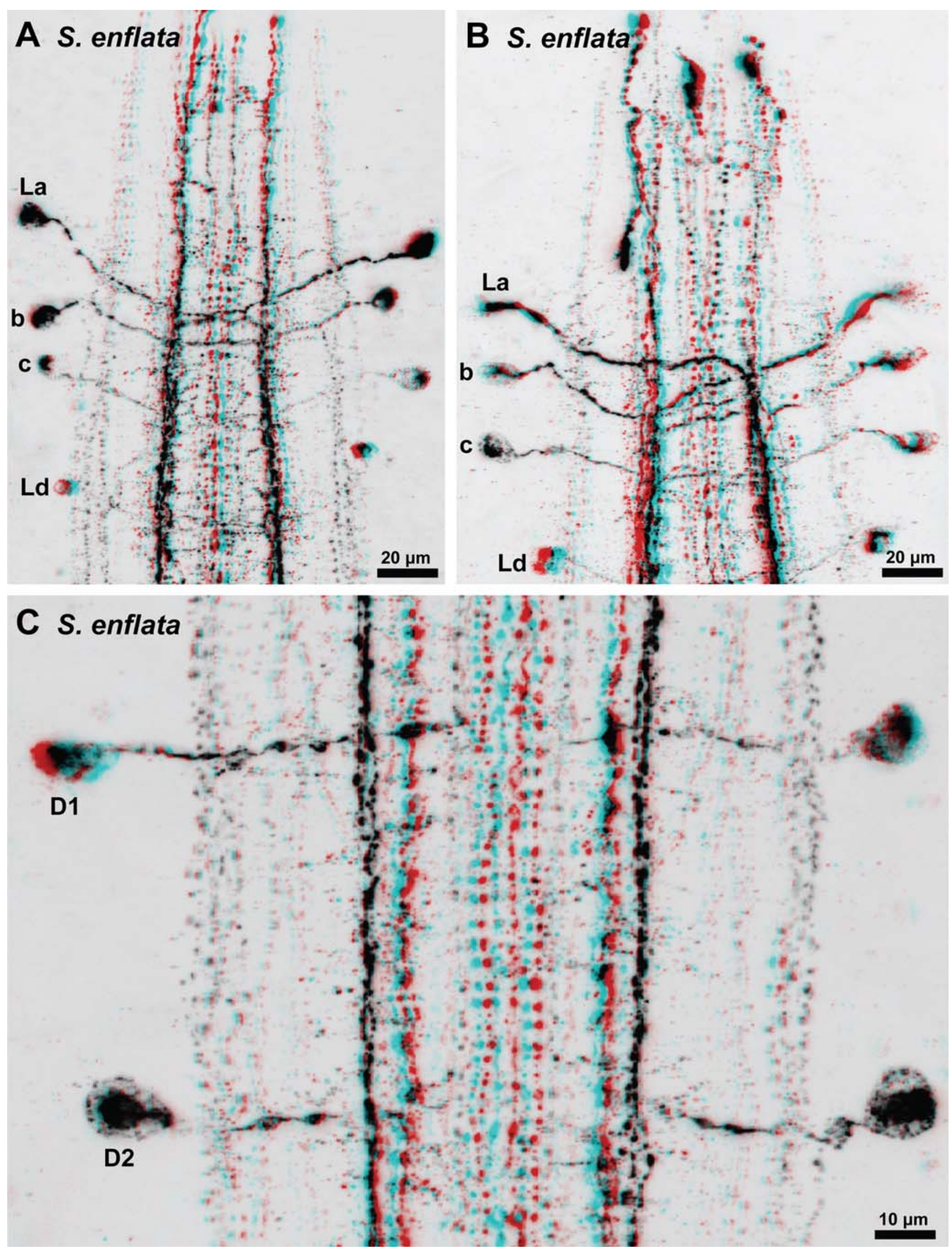




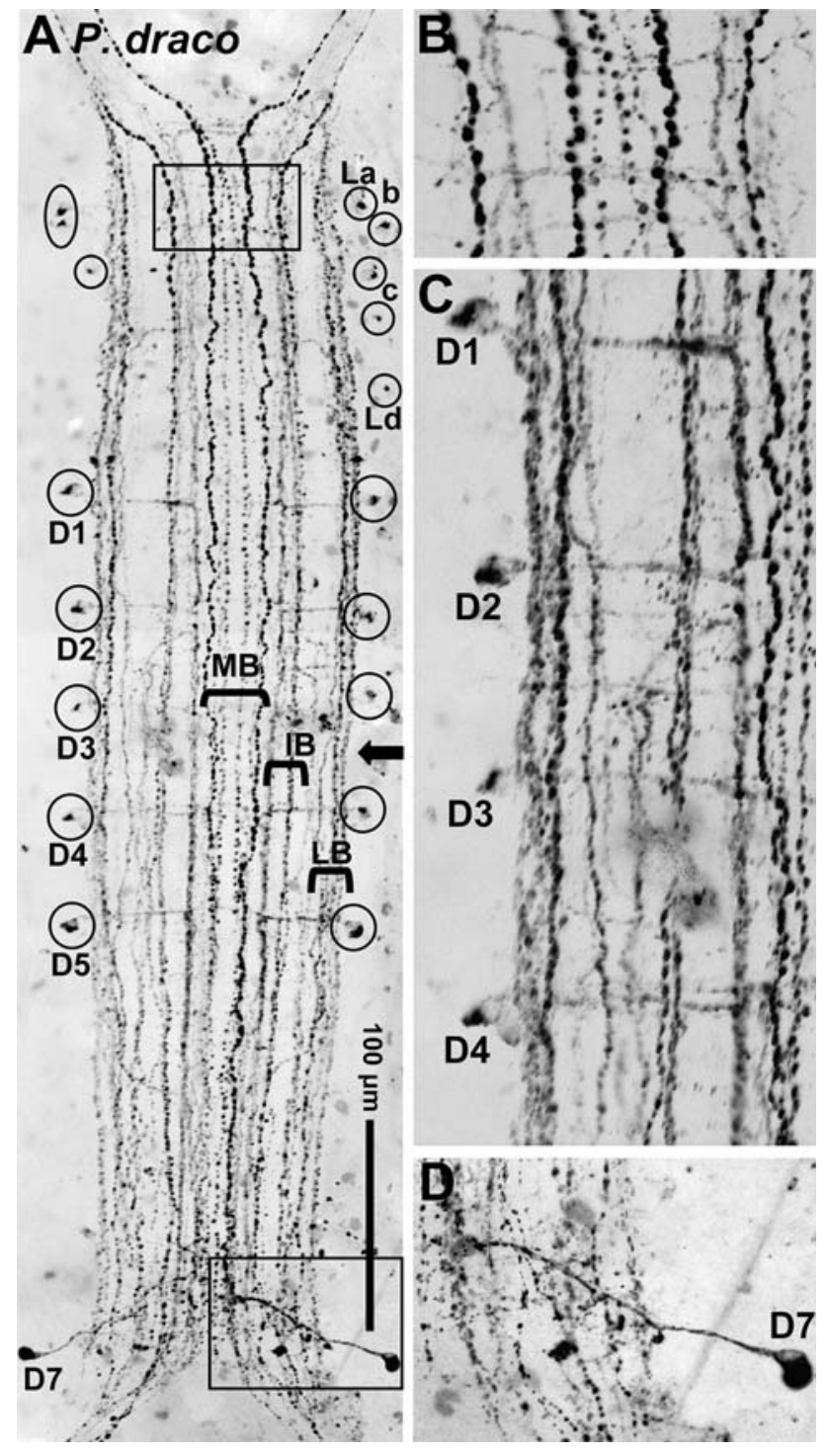

Fig. 9 Paraspadella draco. Ventral views of a wholemount specimen, confocal laser-scan microscopy (black-white inverted images). Localization of RFamide-like immunoreactivity in the ventral nerve centre of a single specimen. a Low power view; individually identifiable neurons are encircled and labelled with letters (for details see text). Abbreviations identify the longitudinal bundles: $I B$ intermediate bundle, $L B$ lateral bundle, $M B$ medial bundle. $\mathbf{b}$ Higher magnification of the anterior boxed area in a. c Higher magnification of the series of $D$ neurons (D1-D4). d Higher magnification of the lower boxed area in a to show cell $D 7$

the previous $L c$ neuron and the following D1 cell (Figs. $5 \mathrm{~b}, \mathrm{c}, 10 \mathrm{~b}, \mathrm{c}$ ). The arrangement of the $L a-d$ neurons was consistent between individual specimens of $S$. cephaloptera ("intraspecific homology" in the nomenclature established by Kutsch and Breidbach 1994) and their moNSrphology was very similar to that of the $L$ neurons in $S$. enflata, including the contralaterally crossing neurites that target the intermediate bundle. This architecture suggests a homology of the S. enflata and the S. cephaloptera $L$ neurons. Contrary to representatives of the genera Sagitta and Pterosagitta, the series of $D$ neurons comprised seven and not only six cells as in S. cephaloptera. In addition, a conspicuous giant neuron, termed the $X$ neuron, was present between the $D 6$ and $D 7$ cells (Fig. 10b, c). In some specimens, additional unidentified neurons were labelled (arrows in Fig. 10b). The course of the fibres that the $D$ neurons extend could only be analysed for $D 5-D 7$ and $X$. Their neurites exit the somata in a medial direction to crossover the lateral and intermediate bundles. We could not determine if the neurites then cross-over to the contralateral side or if they target the medial fibre bundle (Fig. 10b, c).

\section{Discussion}

Ultrastructure of the ventral nerve centre: evidence for serially arranged elements?

Our electron microscopical observations in Spadella cephaloptera add new insights into the fine structural organization of a chaetognath ventral nerve centre. In addition to those studies addressing the general anatomy of the chaetognath nervous system (e.g. Hertwig 1880; Grassi 1883; von Ritter-Zahony 1908; Burfield 1927; John 1933; Kuhl 1938; Hyman 1959) a considerable amount of work has been dedicated to understanding the fine structural architecture of the brain including the retrocerebral organ (Scharrer 1965; Rehkämper and Welsch 1985; Goto and Yoshida 1987; Bone and Goto 1991; Shinn 1997), of the cephalic or trunk sense organs connected to the central nervous system (eyes: e.g. Eakin and Westfall 1964; Ducret 1975; Goto et al. 1984, 1989; Goto and Yoshida 1985; ciliary fence organs: e.g. Welsch and Storch 1983; Malakhov et al. 2005; corona ciliata: e.g. Giulianini et al. 1999; Malakhov et al. 2005; solitary head sensilla: Bone and Pulsford 1978, 1984), of the intraepidermal nerve plexus (Ahnelt 1980, 1984), and of the neuromuscular junctions in visceral and skeletal musculature (Duvert and Barets 1983). However, the majority of these contributions are based on the examination of pelagic chaetognaths with most of them dedicated to species of the genus Sagitta. When not considering those papers dealing with the cephalic nervous system and herewith associated sense organs, there remain few studies comprehensively dealing with the ventral nerve centre fine structure. Only the works of Ahnelt (1980: Fig. 159), Bone and Pulsford (1984: Figs. 25, 26, 27, 28, 29), Goto and Yoshida (1987: Fig. 17a-c), and Bone and Goto (1991: Fig. 3.9) provided some TEM images showing components of the ventral nerve centre of five species of Sagitta, which are useful for a comparison with our data. The fine structure of the ventral nerve centre in benthic Chaetognatha are even less well documented. Only Ahnelt (1980) published a 


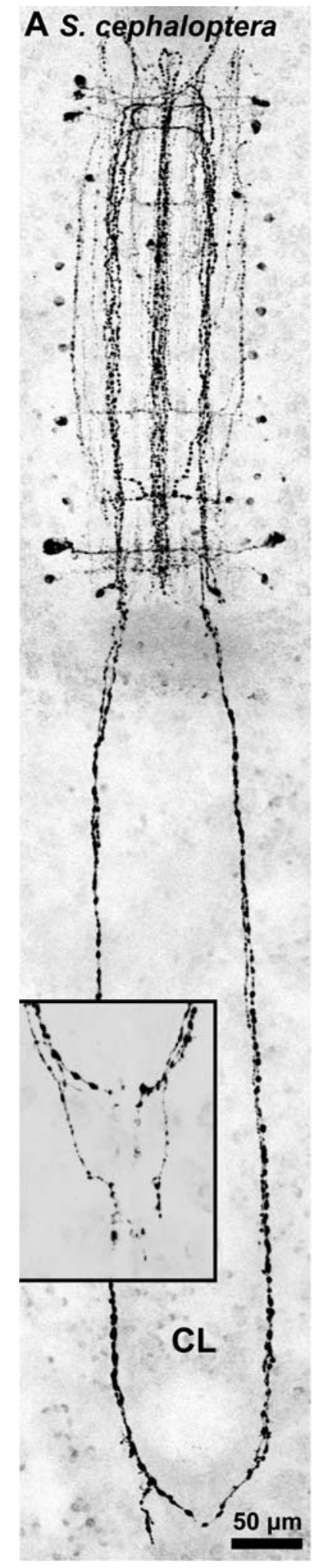

B S. cephaloptera

C S. cephaloptera
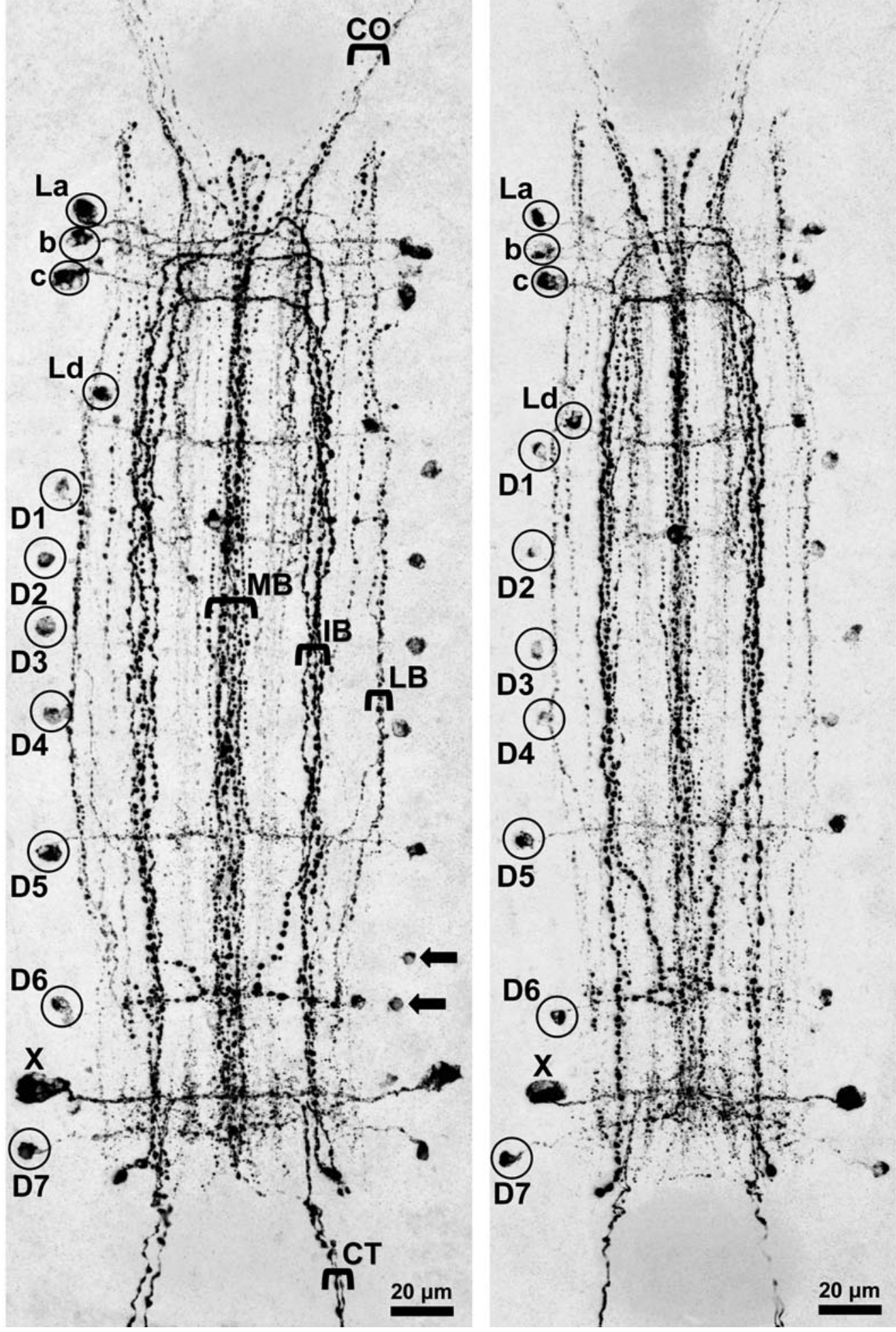

Fig. 10 Spadella cephaloptera. Ventral views of whole mount specimens, confocal laser-scan microscopy (black-white inverted images). Localization of RFamide-like immunoreactivity in the ventral nerve centre. The inset in a shows the posterior part of the caudal loop in a different specimen to show the fibre branches that come off the posterior part of the caudal loop. b Higher magnification of the specimen

shown in a. c Shows a second specimen to illustrate that the labelling pattern is almost identical between different specimens. Individually identifiable neurons are encircled and labelled with letters (for details see text). Arrows in $\mathbf{b}$ label additional unidentified neurons. $C L$ caudal loop, $C O$ main connective, $C T$ caudal tract, $I B$ intermediate bundle, $L B$ lateral bundle, $M B$ medial bundle 
transverse section through the dorsolateral periphery of the ventral nerve centre of $S$. cephaloptera showing the transition zone between one lateral somata cluster and the neuropil core. This author (Ahnelt 1984) already noted the intense coating of the ventral nervous centre with functionally transformed proximal epidermal cells in S. cephaloptera. Our report of the epidermal sheath confirms his observations and also adds more details on the serially fenestrated complex of proximal epidermal cells that extends between the lateral somata clusters and the central (median) neuropil.

Bone and Pulsford (1984) mentioned the presence of "two pairs of large neuron somata" (p. 218) in the ventral nerve centre of Sagitta spp. but did not provide a more detailed description of these neurons. We suggest that these large neurons at the ventromedian margin of the lateral somata clusters in the ventral nerve centres of S. setosa (see Harzsch and Müller 2007, Fig. 6c, d) and S. cephaloptera (this study, e.g. Fig. 9b) may be comparable. However, any comparison of neuron types based on fine structural features between different taxa should be conducted with care, because different physiological conditions may be "frozen" in certain neurons at the time of fixation, even though they might belong to the same type. A comprehensive comparative fine structural study of the ventral nerve centres of a variety of pelagic and benthic chaetognath taxa may reveal new or support already presumed neuronal identities.

The glial packing of ventral nerve centre neurons depicted here in S. cephaloptera appears to reflect a common principle of a functional assembly of neurons in the nervous system of chaetognaths. Described for the ventral nerve centre of S. crassa (Bone and Pulsford 1984), the grouping of somata has also been documented to occur in the cerebral ganglion ( $S$. setosa: Rehkämper and Welsch 1985: Fig. 3b; S. hexaptera: Goto and Yoshida 1987: Fig. 6a) and the vestibular ganglia (S. hexaptera: Goto and Yoshida 1987: Fig. 11a). Future studies with immunohistochemical markers in combination with TEM and neuronal tract tracing methods may shed light on the questions whether the neurons in those packages are morphologically similar, share corresponding projection patterns and may also be functionally related.

In addition to the individually identified RFamidergic neurons, e.g. of the $\mathrm{D}$ series that will be discussed below, there is more evidence for serialities in the ventral nerve centre. Harzsch and Müller (2007), using an immunohistochemical marker for synaptic proteins reported an array of microcompartments in the neuropil of the ventral nerve centre of $S$. setosa. Also in S. setosa, Bone and Pulsford (1984) mentioned "constant arrangements" of large transverse fibres, paired large somata, and ciliary fence organs along the body surface as being serially arranged and in reproducibly identifiable positions. Bone and Pulsford
(1984) furthermore assumed that constant patterns might also be expected for all other, "smaller neurons." We tentatively suggest the repeated arrangement of packages of neurons and the iterated passages of neurite bundles through gaps in the proximal epidermal layer as additional structures with a serial arrangement in the chaetognathan ground pattern.

Interspecific identification of individual neurons in Chaetognatha: a new character to explore chaetognath intraphyletic relationships?

The presence of individually identified RFamide-like immunoreactive (RFir) neurons that can be recognized from animal to animal of one species previously has been reported for S. setosa (Bone et al. 1987; Harzsch and Müller 2007). More specifically, these are the series of $L$ and $D$ neurons and these neurons, according to the terminology suggested by Kutsch and Breidbach (1994), can be designated as displaying intraspecific homology. In the present report, we provide examples for individually identifiably neurons with intraspecific homology for three more chaetognath species, Sagitta enflata, Pterosagitta draco, and S. cephaloptera, so that, together with the data on Paraspadella gotoi by Goto et al. (1992) it seems likely that the potential to generate neurons with individual identities is part of the ground pattern of Chaetognatha. More importantly, our study for the first time provides evidence that specific neurons can be homologized between different species of Chaetognatha ("interspecific homology" according to Kutsch and Breidbach 1994). Based on a biochemical criterion, the common expression of RFamide-related neuropeptides, and based on morphological criteria such as the position of the neuronal somata in relation to the architectural framework of the ventral nerve centre as well as the course of their neurites we suggest that the neurons D1-D5 and $D 7$ can be homologized between all the species studied here. The correspondence of the $L$ neurons in these taxa is not so clear, because their axonal morphology is poorly resolved in S. setosa (Harzsch and Müller 2007). However, there is a striking similarity between the $L$ neurons of $S$. enflata and $S$. cephaloptera suggesting that these neurons can be homologized even between the members of two different chaetognath genera. Yet, the course of the neurites of the $D$ neurons is slightly different between the representatives of Sagitta and Spadella: whereas in S. cephaloptera the $D$ neurites course medially as far as the medial longitudinal fibre bundle, in the two Sagitta species studied these neurites target the intermediate bundle and only in some cases small branches extend more medially towards the medial bundle. In addition, our immunolocalizations provide evidence for the presence of more RFir neurons in Spadella than in Sagitta. 
This finding extends a previous report by Goto et al. (1992) on representatives of the genus Paraspadella. Although the authors did not describe the course of the neurites in great detail, they identified two pairs of RFir neurons in the posterior part of the ventral nerve centre named "posterior somata." Considering their position in the ventral nerve centre, it is likely that these somata correspond to the $D 6$ and $X$ neurons found in the present study which implies that these neurons can be recognized as two apomorphies of the Spadellidae. In Paraspadella gotoi, Goto et al. (1992: Fig. 1f) described a single RFir bipolar neuron located outside of the ventral nerve centre close to the tail. This neuron extends a posterior neurite that branches in the tail region as well as an anteriorly directed neurite that connects to the caudal loop. Although S. cephaloptera has a similarly unpaired fibre that innervates the tail region we did not trace a neuronal cell soma associated with this fibre but assume that it originates in the caudal loop in this species.

\section{Conclusion}

In Arthropoda, the morphology of individually identified serotonin-immunoreactive neurons in the ventral nerve cord has been used to contribute new characters to the discussion on arthropod phylogeny (review Harzsch et al. 2005; Harzsch 2006). In species of the Insecta, there are many examples for identified neurons the architecture of which is surprisingly similar across all taxa that have been examined, e.g. a serotonergic olfactory interneuron that innervates the antennal lobe (see review by Schachtner et al. 2005) or dorsal unpaired octopaminergic neurons in the ventral nerve cord (see review by Pflüger and Stevenson 2005). Along these lines, our current report raises the possibility that analysing the morphology of individual neurons in additional chaetognath species may also contribute useful characters for reconstructing chaetognath phylogeny. That way, it may for example be possible to gain new insights into the disputed phylogenetic relationship of Pterosagitta draco (Papillon et al. 2006), in which the pattern of RFamidergic neurons shows conspicuous similarities to Sagitta spp. rather than to Spadella spp. However, for such an effort a much broader taxon sampling will be needed. More specifically, bentho-planktonic representatives such as the presumably basally branching taxon Heterokrohniidae (Papillon et al. 2006) need to be studied for a broad coverage of Chaetognatha. With such an expanded data set it may also be possible to discuss, e.g. the evolutionary relationship between the $D$ neuron architecture in Sagitta versus Spadella. The Spadella $D$ neurons could for example be derived from the Sagitta $D$ neurons by a medial extension of the main neurite. Alternatively, the Sagitta D neurons could have originated from the Spadella type by a restriction of the primary neurite.

However, more data will be necessary to decide what the primary architecture may be here. Another intriguing observation is that in Spadella species, the morphology of the $L$ and $D$ neurons is more similar to each other than in Sagitta species. One possible explanation may be that initially, Chaetognatha had a series of serially iterated neurons with an identical morphology which during subsequent evolution differentiated into morphologically distinct subsets. Once again, the ancestral architecture of the arrow worm nervous system will be reconstructed when a broader taxon sampling will be available.

The species studied in the present report belong to the Aphragmophora (Sagittidae) and Phragmophora (Spadellidae), which constitute the two main taxonomic groups of the Chaetognatha. These two taxa were characterized by Tokioka (1965) based on the presence (Phragmophora) and absence (Aphragmophora) of transverse muscles (phragms). A recent molecular analysis of the intraphyletic relationships has revealed the variability of this character (homoplasy) and highlighted the influence of the life style on chaetognath morphology, particularly for benthic species that adapt to a planktonic lifestyle (Papillon et al. 2006). The functional significance of RFamide peptides in metazoans is an intense field of research and one of the emerging themes is the remarkable conservation in control of feeding (Dockray 2004) and mating (Kriegsfeld 2006) behaviours both in Protostomia and Deuterostomia as well as in cnidarians (Pernet et al. 2004). A thorough interspecific comparative analysis of RFir neurons is likely to provide more insights into how the variations in the organization of the muscular and nervous systems in Chaetognatha correlate with their diverging life styles as well as their feeding and mating behaviours.

Acknowledgments We would like to thank the team of the "Gastforschung" at the Biologische Anstalt Helgoland for assistance in collecting Sagitta setosa. Planktonic samples collected in the Indian Ocean were kindly provided by Gisèle Champalbert and Marc Pagano from the Institut pour la Recherche et le Développement (IRD UR 167 SyRoCo). We gratefully acknowledge the assistance by Prof. Dr Ludwig Jonas and his technician team from the Electron Microscopic Centre of the University of Rostock, by Dr Walter Richter and colleagues of the Electron Microscopic Centre of the Friedrich-Schiller-University Jena, and by Christa Ladwig from the Electron Microscopic Unit of the University Hospital Essen. Our special thanks go to Dr George Shinn for providing fixed specimens of S. hispida. This study was supported by grant HA 2540/7-1 in the DFG focus programme „Metazoan Deep Phylogeny" and by the Max Planck Society.

Open Access This article is distributed under the terms of the Creative Commons Attribution Noncommercial License which permits any noncommercial use, distribution, and reproduction in any medium, provided the original author(s) and source are credited. 


\section{References}

Ahnelt P (1980) Das Coelom der Chaetognathen. Thesis, University of Vienna, 209 pp +178 figs

Ahnelt P (1984) Chaetognatha, chapter 40. In: Bereiter-Hahn J, Matoltsy AG, Richards KS (eds) Biology of the integument. vol 1. Invertebrates. Springer, New York, pp 746-755

Arnaud J, Brunet M, Mazza J (1978) Studies on the midgut of Centropages typicus (Copepoda, Calanoida). I. Structural and ultrastructural data. Cell Tissue Res 187:333-353. doi:10.1007/ BF00224375

Bone Q, Goto T (1991) The nervous system. In: Bone Q, Kapp H, Pierrot-Bults AC (eds) The biology of Chaetognaths. Oxford University Press, Oxford, pp 18-31

Bone Q, Pulsford A (1978) The arrangement of ciliated sensory cells in Spadella (Chaetognatha). J Mar Biol Assoc UK 58:565-570

Bone Q, Pulsford A (1984) The sense organs and ventral ganglion of Sagitta (Chaetognatha). Acta Zool Stockh 65:209-220

Bone Q, Grimmelikhuijzen CLP, Pulsford A, Ryan KP (1987) Possible transmitter functions of acetylcholine an an RFamide-like substance in Sagitta (Chaetognatha). Proc R Soc Lond B Biol Sci 230:1-14

Brodfuehrer PD, Thorogood MSE (2001) Identified neurons and leech swimming behavior. Prog Neurobiol 63:371-381. doi:10.1016/ S0301-0082(00)00048-4

Burfield ST (1927) Sagitta. LMBC Proc Trans Liverp Biol Soc 41:1104

Burrows M (1996) The neurobiology of an insect brain. Oxford University Press, Oxford, pp 1-704

Choi JC, Choi Y, Hur KD, Kim CH, Shaw C, Maule AG et al (1996) Platyhelminth FMRFamide-related peptides. Int $\mathrm{J}$ Parasitol 26:335-345. doi:10.1016/0020-7519(96)00012-4

Dockray GJ (2004) The expanding family of -RFamide peptides and their effects on feeding behaviour. Exp Physiol 89:229-235. doi:10.1113/expphysiol.2004.027169

Ducret F (1975) Structure et ultrastructure de l'oeil chez les chaetognathes (gères Sagitta et Eukrohnia). Cah Biol Mar 16:287-300

Dunn CW, Hejnol A, Matus DQ et al (2008) Broad phylogenomic sampling improves resolution of the animal tree of life. Nature 452(7188):745-749. doi:10.1038/nature06614

Duvert M, Barets AL (1983) Ultrastructural studies of neuromuscular junctions in visceral and skeletal muscles of the chaetognath Sagitta setosa. Cell Tissue Res 233:657-669. doi:10.1007/ BF00212233

Duvert M, Salat C (1990) Ultrastructural and cytochemical studies on the connective tissue of chaetognaths. Tissue Cell 22:865-878. doi:10.1016/0040-8166(90)90049-F

Duvert M, Savineau JP (1986) Ultrastructural and physiological studies of the contraction of the trunk musculature of Sagitta setosa (chaetognath). Tissue Cell 18:937-952. doi:10.1016/00408166(86)90048-0

Duvert M, Gros D, Salat C (1980) Ultrastructural studies of the junctional complex in the musculature of the arrow-worm (Sagitta setosa) (Chaetognatha). Tissue Cell 12:1-11. doi:10.1016/00408166(80)90048-8

Eakin RM, Westfall JA (1964) Fine structure of the eye of a chaetognath. J Cell Biol 21:115-132. doi:10.1083/jcb.21.1.115

Fairweather I, Halton DW (1991) Neuropeptides in plathyelminths. Parasitology 102(Suppl):77-92

Friedrich S, Wanninger A, Brückner M, Haszprunar G (2002) Neurogenesis in the mossy chiton, Mopalia muscosa (Gould) (Polyplacophora): evidence against molluscan metamerism. J Morphol 253:109-117. doi:10.1002/jmor.10010

Gaus G, Doble KE, Price DA, Greenberg MJ, Lee TD, Battelle BA (1993) The sequences of five neuropeptides isolated from
Limulus using antisera to FMRFamide. Biol Bull 184:322-329. doi: $10.2307 / 1542450$

Gilchrist LS, Klukas KA, Jellies J, Rapus J, Eckert M, Mesce KA (1995) Distribution and developmental expression of octopamine-immunoreactive neurons in the central nervous system of the leech. J Comp Neurol 353:451-461. doi:10.1002/cne. 903530312

Giulianini PG, Ghirardelli E, Ferrero EA (1999) Ultrastruttura comparativa della corona ciliate in Spadella cephaloptera e Sagitta seto$s a$ (Chaetognatha). Biol Mar Medit 6:666-669

Goto T, Yoshida M (1985) Photoreception in Chaetognatha. In: Ali MA (ed) Photoreception and vision in invertebrates. Plenum Publishing Corporation, New York, pp 727-742

Goto T, Yoshida M (1987) Nervous system in Chaetognatha. In: Ali MA (ed) Nervous systems in invertebrates. Plenum Publishing Corporation, New York, pp 461-481

Goto T, Takasu N, Yoshida M (1984) A unique photoreceptive structure in the arrowworms Sagitta crassa and Spadella schizoptera (Chaetognatha). Cell Tissue Res 235:471-478. doi:10.1007/ BF00226941

Goto T, Terazaki M, Yoshida M (1989) Comparative motphology of the eyes of Sagitta (Chaetognatha) in relation to depth of habitat. Exp Biol 48:95-105

Goto T, Katayama-Kumoi Y, Tohyama M, Yoshida M (1992) Distribution and development of the serotonin-and RFamide-like immunoreactive neurons in the arrowworm, Paraspadella goto $i$ (Chaetognatha). Cell Tissue Res 267:215-222. doi:10.1007/ BF00302958

Grassi E (1883) I Chetognathi. Fauna Flora Neapels 5:1-126

Greenberg MJ, Price DA (1992) Relationships among the FMRFamide-like peptides. Prog Brain Res 92:25-37. doi:10.1016/ S0079-6123(08)61162-0

Grimmelikhuijzen CJP (1985) Antisera to the sequence Arg-Pheamide visualize neuronal centralization in hydroid polyps. Cell Tissue Res 241:171-182. doi:10.1007/BF00214639

Grimmelikhuijzen CJP, Spencer AN (1984) FMRFamide immunoreactivity in the nervous system of the medusa Polyorchis penicillatus. J Comp Neurol 230:361-371. doi:10.1002/cne.902300305

Grimmelikhuijzen CJP, Cartensen K, Darmer D, Moosler A, Nothacker HP, Reinscheid RK et al (1992) Coelenterate neuropeptides: structure, action and biosynthesis. Am Zool 32:1-12

Groome JR (1993) Distribution and partial characterization of FMRFamide-like peptides in the horeseshoe crab, Limulus polyphemus. Comp Biochem Physiol 104C:79-85

Halton DW, Gustafsson MKS (1996) Functional morphology of the plathyhelminth nervous system. Parasitology 113:47-72

Harzsch S (2006) Neurophylogeny: architecture of the nervous system and a fresh view on arthropod phylogeny. Integr Comp Biol 46:162-194. doi:10.1093/icb/icj011

Harzsch S, Müller CHG (2007) A new look at the ventral nerve centre of Sagitta: implications for the phylogenetic position of Chaetognatha (arrow worms) and the evolution of the bilaterian nervous system. Front Zool 4:14. doi:10.1186/1742-9994-4-14

Harzsch S, Müller CHG, Wolf H (2005) From variable to constant cell numbers: cellular characteristics of the arthropod nervous system argue against a sister-group relationship of Chelicerata and "Myriapoda" but favour the Mandibulata concept. Dev Genes Evol 215:53-68. doi:10.1007/s00427-004-0451-z

Hertwig O (1880) Die Chaetognathen. Mon Jena Z Med Naturw 14:196-311

Homberg U (1994) Distribution of neurotransmitters in the insect brain. Prog Zool 40:1-88

Huang Y, Jellies J, Johansen KM, Johansen J (1998) Development and pathway formation of peripheral neurons during leech embryogenesis. J Comp Neurol 397:394-402. doi:10.1002/(SICI)10969861(19980803)397:3<394::AID-CNE6>3.0.CO;2-Y 
Hyman LH (1959) Chaetognatha. In: Hyman LH (ed) The invertebrates. Smaller coelomate groups, vol 5. McGraw-Hill, New York, pp 1-71

Imai JH, Meinertzhagen IA (2007) Neurons of the ascidean larval nervous system in Ciona intestinalis: I. Central nervous system. J Comp Neurol 501:316-334. doi:10.1002/cne.21246

John CC (1933) Habits, structure and development of Spadella cephaloptera. Q J Microsc Sci 75:625-696

Kapp H (2007) Chaetognatha, Pfeilwürmer. In: Westheide W, Rieger R (eds) Spezielle Zoologie Teil 1. Gustav Fischer Verlag, Stuttgart, pp 898-904

Karnovsky MJ (1965) A formaldehyde-glutaraldehyde fixative of high osmolality for use in electron microscopy. J Cell Biol 27:137-138

Keller R (1992) Crustacean neuropeptides: structures, functions and comparative aspects. Experientia 48:439-448. doi:10.1007/ BF01928162

Kriegsfeld LJ (2006) Driving reproduction: RFamide peptides behind the wheel. Horm Behav 50:655-666. doi:10.1016/j.yhbeh.2006. 06.004

Kuhl W (1938) Chaetognatha. In: Bronn HG (ed) Klassen und Ordnungen des Tierreichs. Band 4, Vermes Abteilung 4, Buch 2, Teil 1. Akademische Verlagsgesellschaft Goest \& Portig KG, Leipzig, pp 1-226

Kutsch W, Breidbach O (1994) Homologous structures in the nervous system of Arthropoda. Adv Insect Physiol 24:1-113. doi:10.1016/ S0065-2806(08)60082-X

Malakhov VV, Berezinskaya TL, Solovyev KA (2005) Fine structure of sensory organs in chaetognaths: ciliary fence receptors, ciliary tuft receptors and ciliary loop. Invert Zool 2:67-77 (in Russian)

Marlétaz F, Gilles A, Caubit X, Perez Y, Dossat C, Samain S et al (2008) Chaetognath transcriptome reveals ancestral and unique features among bilaterians. Genome Biol 9(6):R94. doi:10.1186/ gb-2008-9-6-r94

Meinertzhagen IA (2004) Eutely, cell lineage, and fate within the ascidian larval nervous system: determinacy or to be determined? Can J Zool 83:1-12

Meinertzhagen IA, Lemaire P, Okamura Y (2004) The neurobiology of the ascidian tadpole larva: recent developments in an ancient chordate. Annu Rev Neurosci 27:453-485. doi:10.1146/annurev.neuro.27.070203.144255

Müller MCM (2006) Polychaete nervous systems: ground pattern and variations-cLS microscopy and the importance of novel characteristics in phylogenetic analysis. Integr Comp Biol 46:125-133. doi:10.1093/icb/icj017

Müller MCM, Sterrer W (2004) Musculature and nervous system of Gnathostomula peregrina (Gnathostomulida) shown by phalloidin labeling, immunohistochemistry, and cLSM, and their phylogenetic significance. Zoomorphology 123:169-177

Muneoka Y, Kobayashi M (1992) Comparatative aspects of structure and action of molluscan neuropeptides. Experientia 48:448-456. doi:10.1007/BF01928163

Nässel DR (1993) Neuropeptides in the insect brain: a review. Cell Tissue Res 273:1-29. doi:10.1007/BF00304608

Nässel DR, Homberg U (2006) Neuropeptides in interneurons of the insect brain. Cell Tissue Res 326:1-24. doi:10.1007/s00441-006$0210-8$

Nielsen C (2001) Animal evolution. Oxford University Press, Oxford

Orrhage L, Müller MCM (2005) Morphology of the nervous system of Polychaeta (Annelida). Hydrobiologia 535(526):79-111

Papillon D, Perez Y, Caubit X, Le Parco Y (2006) Systematics of Chaetognatha under the light of molecular data, using duplicated ribosomal 18S DNA sequences. Mol Phylogenet Evol 38:621634. doi:10.1016/j.ympev.2005.12.004

Pernet V, Anctil M, Grimmelikhuijzen CJ (2004) Antho-RFamidecontaining neurons in the primitive nervous system of the anthozoan Renilla koellikeri. J Comp Neurol 472:208-220. doi:10.1002/cne.20108
Pflüger J, Stevenson PA (2005) Evolutionary aspects of octopaminergic systems with emphasis on arthropods. Arthropod Struct Dev 34:379-396. doi:10.1016/j.asd.2005.04.004

Price DA, Greenberg MJ (1989) The hunting of the FaRPs: the distribution of FMRFamide-related peptides. Biol Bull 177:198-205. doi: $10.2307 / 1541933$

Rehkämper G, Welsch U (1985) On the fine structure of the cerebral ganglion of Sagitta (Chaetognatha). Zoomorphology 105:83-89. doi:10.1007/BF00312142

Reuter M, Halton DW (2001) Comparative neurobiology of Plathelminthes. In: Littlewood DTJ, Bray RA (eds) Interrelationships of Plathyelminthes. Taylor \& Francis, London, pp 239-249

Reuter M, Mäntylä K, Gustafsson KS (1998) Organization of the orthogon-main and minor nerve cords. Hydrobiologia 383:175182. doi: $10.1023 / \mathrm{A}: 1003478030220$

Schachtner J, Schmidt M, Homberg U (2005) Organization and evolutionary trends of primary olfactory brain centers in Tetraconata (Crustacea+Hexapoda). Arthropod Struct Dev 34:257-299. doi:10.1016/j.asd.2005.04.003

Scharrer E (1965) The fine structure of the retrocerebral organ of Sagitta (Chaetognatha). Life Sci 4:923-926. doi:10.1016/00243205(65)90191-8

Shinn GL (1997) Chaetognatha. In: Harrison FW, Ruppert EE (eds) Microscopic anatomy of invertebrates, vol 15: Hemichordata, Chaetognatha, and the invertebrate chordates. Wiley-Liss Inc, New York, pp 103-220

Soviknes AM, Chourrout D, Glover JC (2007) Development of the caudal nerve cord, motoneurons, and muscle innervation in the appendicularian urochordate Oikopleura dioica. J Comp Neurol 503:224-242. doi:10.1002/cne.21376

Stach T (2005) Comparison of the serotonergic nervous system among Tunicata: implications for its evolution within Chordata. Org Divers Evol 5:15-24. doi:10.1016/j.ode.2004.05.004

Stuart DK, Blair SS, Weisblat DA (1987) Cell lineage, cell death, and the developmental origin of identified serotonin- and dopaminecontaining neurons of the leech. J Neurosci 7:1107-1122

Tokioka T (1965) The taxonomical outline of chaetognaths. Publ Seto Mar Biol Lab 12:335-357

Vannier J, Steiner M, Renvoise E, Hu S-X, Casanova J-P (2007) Early Cambrian origin of modern food webs: evidence from predator arrow worms. Proc R Soc Lond B Biol Sci 274:627-633. doi:10.1098/rspb.2006.3761

von Ritter-Zahony R (1908) Zur Anatomie des Chaetognathenkopfes. Denkschr Akad Wiss Wien 84:33-41

Voronezhskaya EE, Tyurin SA, Nezlin LP (2002) Neuronal development in larval chiton Ischnochiton hakodadensis (Mollusca: Polyplacophora). J Comp Neurol 444:25-38. doi:10.1002/ cne. 10130

Walker RJ (1992) Neuroactive peptides with an RFamide or Famide carboxyl terminal. Comp Biochem Physiol 102C:213-222

Walthall WW (1995) Repeating patterns of motoneurons in nematodes: the origin of segmentation? In: Breidbach O, Kutsch B (eds) The nervous systems of invertebrates: an evolutionary and comparative approach. Birkhäuser Verlag, Basel, pp 61-75

Welsch U, Storch V (1983) Fine structural and enzyme histochemical observations on the epidermis and the sensory cells of Sagitta elegans (Chaetognatha). Zool Anz 210:34-43

White JG, Southgate E, Thomson JN, Brenner S (1986) The structure of the nervous system of the nematode Caenorhabditis elegans. Philos Trans R Soc Lond B Biol Sci 314:1-340. doi:10.1098/ rstb.1986.0056

Wicht H, Lacalli TC (2005) The nervous system of Amphioxus: structure, development, and evolutionary significance. Can J Zool 83:122-150. doi:10.1139/z04-163

Zajac J-M, Mollereau C (2006) Introduction: RFamide peptides. Peptides 27:941-942. doi:10.1016/j.peptides.2005.12.005 